San Jose State University

SJSU ScholarWorks

Master's Theses

Master's Theses and Graduate Research

2005

\title{
Effect of mechanical strain on gastric smooth muscle cell cultures in vitro
}

Errol Omaar Ozdalga

San Jose State University

Follow this and additional works at: https://scholarworks.sjsu.edu/etd_theses

\section{Recommended Citation}

Ozdalga, Errol Omaar, "Effect of mechanical strain on gastric smooth muscle cell cultures in vitro" (2005). Master's Theses. 2831.

DOI: https://doi.org/10.31979/etd.ywdr-dsp7

https://scholarworks.sjsu.edu/etd_theses/2831

This Thesis is brought to you for free and open access by the Master's Theses and Graduate Research at SJSU ScholarWorks. It has been accepted for inclusion in Master's Theses by an authorized administrator of SJSU ScholarWorks. For more information, please contact scholarworks@sjsu.edu. 


\section{NOTE TO USERS}

This reproduction is the best copy available.

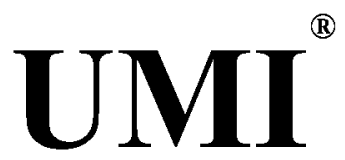





\author{
A Thesis \\ Presented to \\ The Faculty of the Department of Biology \\ San Jose State University
}

In Partial Fulfillment

of the Requirements for the Degree

Master of Science

\author{
By \\ Errol Omaar Ozdalga
}

December 2005 
UMI Number: 1432449

\section{INFORMATION TO USERS}

The quality of this reproduction is dependent upon the quality of the copy submitted. Broken or indistinct print, colored or poor quality illustrations and photographs, print bleed-through, substandard margins, and improper alignment can adversely affect reproduction.

In the unlikely event that the author did not send a complete manuscript and there are missing pages, these will be noted. Also, if unauthorized copyright material had to be removed, a note will indicate the deletion.

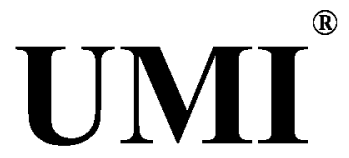

UMI Microform 1432449

Copyright 2006 by ProQuest Information and Learning Company. All rights reserved. This microform edition is protected against unauthorized copying under Title 17, United States Code.

ProQuest Information and Learning Company 300 North Zeeb Road

P.O. Box 1346

Ann Arbor, MI 48106-1346 
(C) 2005

Errol Omaar Ozdalga

ALL RIGHTS RESERVED 


\section{APPROVED FOR THE DEPARTMENT OF BIOLOGY}
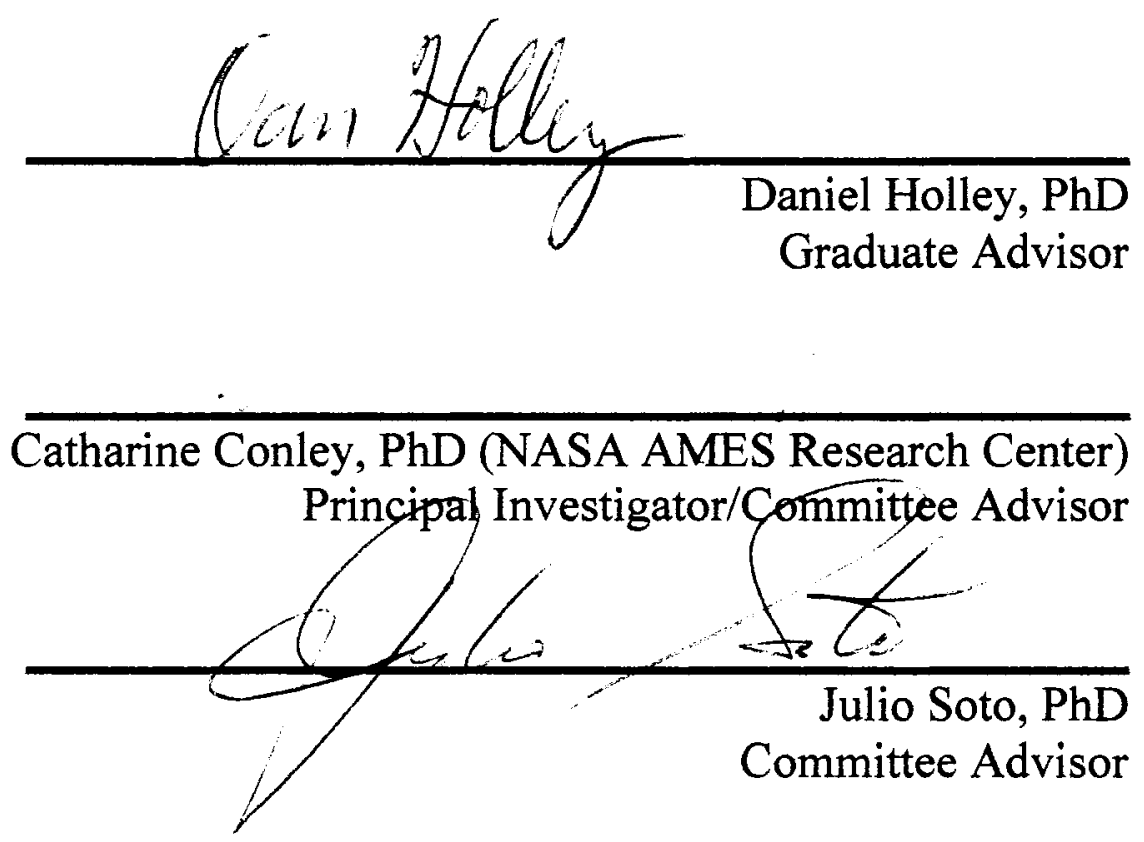

APPROVED FOR THE UNIVERSITY

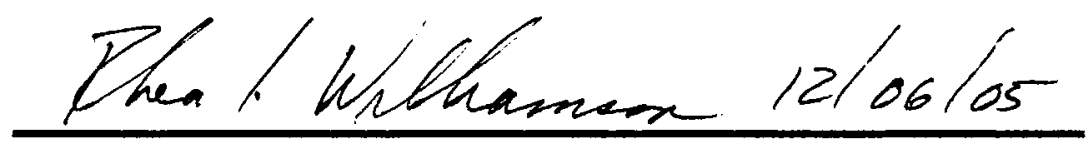




\section{ABSTRACT \\ EFFECT OF MECHANICAL STRAIN ON GASTRIC SMOOTH MUSCLE CELL CULTURES IN VITRO \\ By Errol Omaar Ozdalga}

The purpose of this study was to characterize leiomodin, tropomodulin, calponin, $\alpha$-actinin, and actin in cultured primary gastric smooth muscle cells (SMC) under mechanical stress. Cells were stained with immunofluorescence and compared both with and without stress. Protein levels were quantitated using western blotting. Calponin staining was used to assess the number of cells in a contractile state. The results of this study indicate that strain increases the number of cells in a contractile state. Strained cells showed both parallel and perpendicular alignment similar to tissue organization within the stomach, indicating that strain might induce a more representative model for gastric SMC studies. Steady-state levels for all five studied proteins did not show a difference between strained and unstrained cells, indicating that contractile state may involve protein localization, rather than turnover. Finally, $\alpha$-actinin and tropomodulin did not co-localize upon staining, indicating distinct localization domains for actin filament ends. 


\section{ACKNOWLEDGEMENTS}

I would like to thank Dr. Daniel Holley, for all the work and support he has done for me as over the past seven years. As a professor, undergraduate advisor, and now graduate advisor, he has played a substantial role in not only helping me achieve great academic goals, but also in realizing that I was capable to achieve them.

I would also like to thank Dr. Julio Soto. During some of the most difficult times throughout this project, Dr. Soto opened up his lab to me and treated me like I was one of his own students. I can only hope one day to be able to display a type of commitment he has to research and the education of his students. I can truly say, that I would not have been able to accomplish this work, if he had not been there for me.

To Dr. Robert Fowler, Linda Olson, and all the other professors and staff in the San Jose State Biological Department as well as the researchers at NASA Ames Research Center who are too numerous to name, I thank you very much for all your support and help with this project. There are at least twenty other professors and researchers whose help on this project was crucial to my success.

To Hoan Tran, a friend and now a colleague, thank you for your support. You made this project even more enjoyable.

And finally, to Dr. Catharine Conley, I am honored to have had the privilege to work in your lab and learn a great deal of what it is to conduct biological research. Throughout my work, you had many obstacles to overcome and yet you were always there to support me in my endeavors. Thank you for taking the time to further my education and increase my confidence. 


\section{TABLE OF CONTENTS}

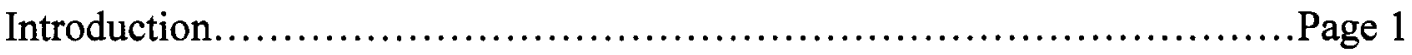

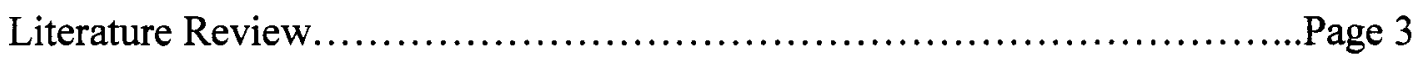

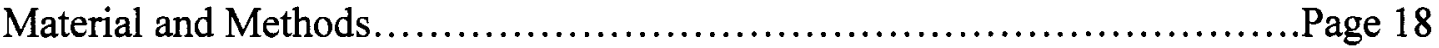

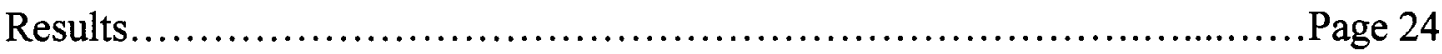

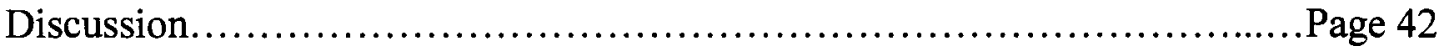

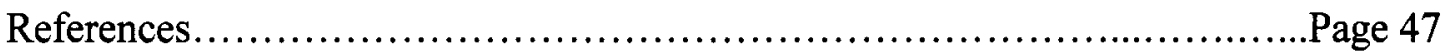




\section{LIST OF FIGURES}

Figure \#

Figure 1 Organization of actin and myosin within the smooth muscle cell.

Figure 2 Location where pictures were taken within strained and non-strained wells $(25 \mathrm{~mm})$.

Figure 3 a) Time course of strained and non-strained cells expressing calponin. b) Example of the photomicrograph used to count contractile cells with calponin staining.

Figure 4 Comparison of cells stained for actin (red) at six days after mechanical straining or in a non-strained environment. Pictures represent the edge, halfway between the edge and center (middle), and center of the wells. Cell nuclei stained blue with Hoechst.

Figure 5 Comparison of strained and non-strained wells from edge of the well (highest strain) to center of the well (lowest strain). Middle denotes the halfway point between edge and center of well. Cells stained orange for actin and blue for nuclei. See Figure 2 for diagram of where pictures where taken.

Figure 6 Staining of cells for $\alpha$-actinin (red) and actin (green). Cells shown are representing the two-day through eight-day of both strained and non-strained wells. Pictures are taken at the edge of the wells to represent highest strain or no strain. Cell nuclei stained blue with Hoechst.

Figure 7 Staining of cells for $\alpha$-actinin (red) and calponin (green). Cells shown are representing the two-day through eight-day of both strained and non-strained wells. Pictures are taken at the edge of the wells to represent highest strain or no strain. Cell nuclei stained blue with Hoechst.

Figure $8 \quad$ Staining of cells for $\alpha$-actinin (red) and Tmod/Lmod (green). Cells shown are representing the two-day through eight-day of both strained and non-strained wells. Pictures are taken at the edge of the wells to represent highest strain or no strain. Cell nuclei stained blue with Hoechst.

Figure 9 Digital magnification of $\alpha$-actinin (red) and Tmod/Lmod (green)

Page \# localization of eight-day sample after onset of strain. 
Figure 10a-e Graphical data (of Table 1) from quantitative western blots of actin. Each $\mathrm{Y}$-axis represents the relative number amount of protein and the $\mathrm{X}$-axis represents the time course for strained and non-strained cells.

Figure 11 a) SDS-PAGE after total protein normalization to quantitate relative amounts of actin. b) Western blot to quantitate calponin.

c) Western blot to quantitate $\alpha$-actinin. d) Western blot to quantitate both Tmod and Lmod. Time course was for start of strain (0D), two days through eight days after strain (2S-8S) and two days through eight days in a non-strained environment $(2 \mathrm{~N}-8 \mathrm{~N})$.

Figure 12 Comparison of cells stained for a-actinin (orange) and actin (green) with and without calcium to induce contraction. 


\section{INTRODUCTION}

Little is known regarding the mechanisms of smooth muscle protein organization and remodeling, relative to skeletal and cardiac muscle. A greater understanding of these mechanisms can provide a foundation from which to provide medical intervention to prevent smooth muscle atrophy, which occurs under hypogravity conditions during space flight, prolonged bed-rest, and aging.

The goal of this pilot study is to provide a novel system to study primary cultured gastric smooth muscle cells under mechanical strain. With this system, we hope to show that cultured smooth muscle cells under mechanical strain will behave in a more contractile state as found in gastric smooth muscle tissue. To accomplish this goal, this study aims to characterize five proteins: leiomodin, tropomodulin, calponin, $\alpha$-actinin, and actin. We expect to see an increase in the number of cells in a contractile state under mechanical strain, as indicated by staining for calponin. Additionally, we expect more of the strained cells to have the characteristic contractile spindle-shape. Smooth muscle cells grown in culture without mechanical stress are more likely to flatten out indicating a proliferative state, not a contractile state.

An additional goal of this study is to provide initial characterizations of the steady-state levels of the five proteins (leiomodin, tropomodulin, calponin, $\alpha$-actinin, and actin) using western blotting. If the mechanically strained cells display a greater number of cells in a contractile state as indicated by calponin staining, we expect to see a higher steady-state level of all five proteins, after total protein has been normalized. 
Moreover, co-staining for both tropomodulin and $\alpha$-actinin should reveal different binding domains as they bind opposite ends of actin fibers to regulate actin monomer turnover. $\alpha$-actinin should localize to dense bodies at the fast growing barbed-ends of actin. 


\section{LITERATURE REVIEW}

Smooth muscle cells are found in many organs within the body. In blood vessels, they maintain vascular tone. In the gastrointestinal tract, smooth muscle cells provide peristaltic movement. These cells can also be found in the airway, bladder, uterus, and the penile and clitoral cavernosal sinuses (30). Smooth muscle earns it name due to its unique organization of contractile proteins, which, unlike skeletal and cardiac muscle, produces no striations when viewed under a microscope.

\section{Smooth Muscle Cell and Contraction}

Contraction of the smooth muscle cells occurs via phosphorylation of the light chain of myosin within the cytoskeletal framework. For this to occur, $\mathrm{Ca}^{++}$must enter the cytoplasm. The primary source of $\mathrm{Ca}^{++}$comes from the extracellular fluid, however a secondary source of $\mathrm{Ca}^{++}$can be found in the intracellular stores such as the endoplasmic reticulum (24). Most of the $\mathrm{Ca}^{++}$that enters into the cell to activate contraction flows through a dihydropyridine-sensitive $\mathrm{Ca}^{++}$channel. This channel contains a subunit, which is sensitive to depolarization of the cell. These channels open their gates to allow $\mathrm{Ca}^{++}$to enter the cytoplasm, when the smooth muscle cell receives a signal to depolarize (24).

While the dihydropyridine-sensitive $\mathrm{Ca}^{++}$channel marks a major source of $\mathrm{Ca}^{++}$ entrance, many other channels play a role in eliciting $\mathrm{Ca}^{++}$influx. For example, the parasympathetic nervous system can stimulate $\mathrm{Ca}^{++}$release through nonselective cationic channels via the muscarinic receptor (24). Autonomic neurons have also been shown to 
simulate PX2 receptors expressed by smooth muscle cells. These receptors contain cationic channels, which can be excited in the presence of ATP. Moreover, studies have shown that smooth muscle cells found in the bladder contain stretch-sensitive cationic channels, which can be mechanically activated (24).

Receptors protruding from intracellular organelles such as the endoplasmic reticulum can be stimulated to release $\mathrm{Ca}^{++}$into the cell. Agonists binding to serpentine receptors on the outside of the cell can lead to a $\mathrm{G}$ protein coupled cascade of events which ultimately signals the intracellular compartments (30). Finally, ryanodine receptors within the endoplasmic reticulum also contain $\mathrm{Ca}^{++}$channels, which are capable of being stimulated in the presence of $\mathrm{Ca}^{++}(24)$.

Once $\mathrm{Ca}^{++}$has entered the smooth muscle cell, it binds to calmodulin. This complex can then activate myosin light-chain kinase (MLC kinase). Once activated MLC kinase can phosphorylate the light chain of myosin. Myosin can then bind to actin and the cell can contract.

Another protein important in the regulation of contraction is myosin phosphatase. Once activated, myosin phosphatase is capable of removing the phosphate group on the myosin light-chain, which will diminish its affinity for actin. However, when this protein is phosphorylated, it is inactive (30). This represents a major step in the control of smooth muscle contraction. 


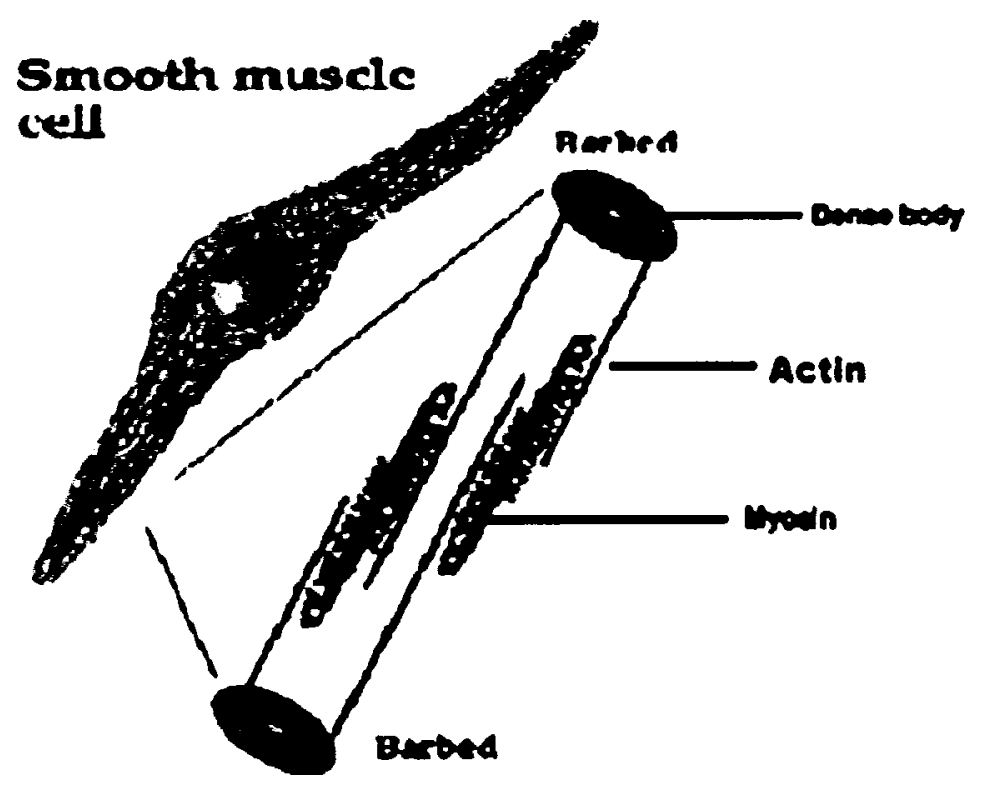

Fig. 1. Organization of actin and myosin within the smooth muscle cell (adapted from Catharine Conley, NASA-Ames Research Center, Mountain View, CA).

The smooth muscle cell uses a variety of mechanisms to restore $\mathrm{Ca}^{++}$levels back to pre-contractile levels and maintain homeostasis. For example, there are $\mathrm{Ca}^{++}$-ATPases in the membrane of the cells that use ATP to pump $\mathrm{Ca}^{++}$out of the cell. Additionally, the endoplasmic reticulum contains specialized $\mathrm{Ca}^{++}$-ATPases called SERCA pumps, which are capable of pumping up to 10,000 -fold the concentration of $\mathrm{Ca}++$ compared to the cytosol (24). Finally, mitochondria have been shown to compartmentalize $\mathrm{Ca}^{++}$. Since mitochondria have a negative potential from the proton pumps of the electron transport chain, $\mathrm{Ca}^{++}$can easily diffuse into these mitochondria via specialized channels (24).

In comparison to skeletal and cardiac muscle, the exact mechanisms that guide the contractile machinery within smooth muscle have eluded scientists. Recently, a change of perspective has lead researchers to suggest that contraction in smooth muscle cells 
operates in a more similar fashion to the movement of non-muscle cells than in the contraction of skeletal cell or cardiac myocytes $(3,5)$.

\section{Actin Assembly}

Actin is the most abundant intracellular protein in eukaryotic cells. In skeletal muscle cells, actin composes 10 percent of the total protein (9). Comparable to histones, actin is one of the most conserved proteins in the cell. Moreover, actin is found in two forms: G-actin and F-actin. G-actin is the monomer form of actin, which polymerizes to create long strands of F-actin. Polymerization begins with the formation of a G-actin trimer.

There are three isoforms of the G-actin monomer: $\alpha$-actin, $\beta$-actin, and $\gamma$-actin. In smooth muscle both $\alpha$-actin and $\gamma$-actin are involved in muscle contraction. Moreover, these two isoforms vary depending of the state of the cell. For example tissue injury could elicit changes in gene expression that alter the ratios of these two isoforms (34). Moreover smooth muscle phenotype drives the assembly and disassembly of actin (7). These phenotypes include a differentiated, contractile, and an undifferentiated migrating or proliferative state. Transmembrane integrin receptors are believed to mediate the extracellular signals that affect actin assembly (15).

Actin filaments are in a continuous state of assembly and disassembly. In vitro, the concentration of free monomers that are in equilibrium with the actin filaments is the critical concentration. As the critical concentration increases, more monomers are 
needed for the same number of actin filaments in order to shift the equilibrium towards the formation of more F-actin (9).

F-actin is a polar filament and it contains functionally different ends: a fast growing, barbed-end and a slow growing, pointed-end. The critical concentration of actin monomers for the pointed-ends is usually twelve to fifteen-fold higher than the barbed-ends under physiologic conditions (9). When the monomer concentration is between the two values for critical concentration, the difference in growth of the two ends of filamentous actin can lead to unidirectional growth where G-actin monomers are being added to the barbed-ends while the pointed-ends are losing monomers. This process is referred to as treadmilling (9).

Furthermore, when monomeric G-actin is in the cytosol, it will be found coupled to an ATP molecule (9). When the molecule is incorporated into an actin filament, a fast occurring reaction leads to the disassociation of one phosphate from ATP, however the phosphate remains bound to the complex. Next, a slower and rate-limiting reaction occurs that leads to the complete disassociation of the phosphate group into the cytosol. Both forms of ATP and ADP that are coupled to the actin molecule have been shown not to be critical in the polymerization process; however, this molecule does play a critical role in actin filament function.

At the pointed-ends, where disassociation of the actin monomers is occurring, ADP coupled to the actin molecule is exchanged for ATP. In vitro, this process is facilitated by the actin-binding protein, profilin (9). 


\section{Actin Binding Proteins}

While some of the most common and important actin-binding proteins are briefly covered here, the actin binding proteins of interest for this paper, the tropomodulins and the leiomodins, will be covered in subsequent sections of this paper.

There have been at least 162 proteins (not including synonyms and isoforms) that are known to bind actin (9). These include membrane-associated proteins, membrane receptors, ion transporters, cross-linking proteins and toxins. The large number of these proteins suggests that actin contains a wide variety of binding sites.

Moreover, actin-binding proteins also regulate the process of treadmilling. This process involves actin molecules being removed from the slow growing end of actin filaments while monomers are added to the fast growing end. It has been shown that the in vitro rate of treadmilling is not sufficient for F-actin to function as it does in the cell.

It is the job of specific actin-binding proteins to regulate the treadmilling action of F-actin in order to control the rate of actin polymerization (9). These actin-binding proteins sequester G-actin. They also cap, sever, cross-link or stabilize the sides of F-actin.

Actin depolymerizing factor (ADF)/cofilin plays an important role in the treadmilling of the actin filament. This is accomplished by ADF/cofilin's ability to increase depolymerization at the pointed-ends of actin. $\mathrm{ADF} / \mathrm{cofilin}$ also binds to ADPactin monomers and inhibits the exchange of the bound nucleotide for ATP (9). As mentioned earlier, this form of G-actin will have a decreased affinity for F-actin incorporation. 
Profilin represents another family of actin binding proteins. Profilin has a high affinity for G-actin, however most of its primary function is to promote the exchange of ATP for ADP of G-actin monomers that have been released from the pointed-ends. Profilin can also facilitate the transport of G-actin to the barbed-ends of actin to promote polymerization (11).

Gelsolin acts on actin by severing actin filaments rapidly. This is illustrated by its ability to dissolve actin gels. It can also cap the barbed-ends of actin. The ability of gelsolin to cap the barbed-ends of actin is directly proportional to the amount of $\mathrm{Ca}^{++}$that is in the cell (9).

Thymosin $\beta 4$ (T $\beta 4$ ) and DNase I can inhibit polymerization by sequestering Gactin. In vascular smooth muscle, $\mathrm{T} \beta 4$ may serve to support angiogenesis by serving as a chemoattractant for endothelial cells (9).

The Arp2/3 complex is a protein complex that is capable of creating branch points for actin filaments near the membrane of the cell (11). It is also considered to be a crosslinking protein. Additionally, CapZ is an actin binding protein that caps the barbed-ends of F-actin. CapZ plays an important regulatory role in the polymerization of F-actin.

Finally, calponin is another protein expressed uniquely in smooth muscle cells. Calponin has been known to bind actin, myosin, $\mathrm{Ca}^{++}$-binding proteins and tropomyosin (10). Although the exact mechanisms of calponin's action in the cell is still controversial, calponin is believed to play a major role in the regulation of contraction in smooth muscle cells $(10,18)$ The central part of the calponin gene codes for two actin binding sites and a myosin binding site (17). It is believed that calponin is able to regulate the 
sliding of actin and myosin filaments by inhibiting actomyosin ATPase activity. This is crucial for smooth muscle contraction $(10,18)$. Conversely, studies looking into the localization of calponin have indicated that calponin interacts only with $\beta$-actin, which is associated with non-muscle functions of actin (18). These studies indicate the need for further understanding of calponin's interaction with actin and other cytoskeletal proteins.

\section{Tropomodulins}

As the actin-binding protein CapZ binds the barbed-ends of an actin filament, a group of proteins called tropomodulins (Tmods) bind the slow growing pointed-ends. To date a total of four unique vertebrates tropomodulin isoforms expressed from different genes have been identified. Tropomodulin-1 (Tmod1) was the first isoform identified (12). Tmod1 is also referred to as E-Tmod, named for its initial identification in erythrocytes. Tmod 1 is found in highest concentrations in erythrocytes, heart muscle and slow-twitch skeletal muscle (19). Another isoform is referred to as Tmod2 and is also named N-tropomodulin as Watakabe et al. first detected it in neural tissue (29). Tmod2 is predominantly expressed during the prenatal period and the first 15 days after birth in rats. Due to its early expression, Tmod 2 is believed to be involved in the dynamic organization of actin in developing as well as mature neurons. It is also expressed in a lower amount in the uterus. Tmod1, also expressed in neurons, may be involved in more long-term stabilization of actin filaments in the cell (29).

The third isoform that has been identified is Tmod3, also named ubiquitous tropomodulin, as it is found in a vast majority of tissue throughout vertebrate organs. 
Tmod3 is the most highly expressed isoform in smooth muscle (5). The fourth isoform, first isolated by Almenar-Queral et al. (1), found in vertebrates is Tmod4. Tmod4 is also named skeletal tropomodulin as it was first identified in skeletal muscle. Tmod4 is predominantly expressed in fast-twitch skeletal muscle, the lens and erythrocytes (1). In skeletal muscle, Tmod4 along with Tmod1 has been shown to bind to nebulin to help regulate its binding to actin (22). Human $T \bmod 2$ and $T \bmod 3$ genes are found on chromosome 15, next to each other while the Tmod4 gene is found on chromosome 1. The Tmod1 gene is found on chromosome $9(5,6)$.

Homologs to the vertebrate tropomodulin genes can been found in flies, $D$. melanogaster and hematode worms, $C$. elegans. Before Tmod3 was identified, studies had shown that among the other three vertebrate Tmod isotypes, their proteins possessed 60-65 percent homology and 75-90 percent similar amino acids $(1,5)$. Tmod is also highly conserved among species. For example, human Tmod1 and chicken Tmod4 proteins are 86 percent identical (13).

Although Tmod caps the pointed-ends of filamentous actin, the affinity of Tmod for F-actin is relatively low. Conversely, the affinity of Tmod for F-actin coupled to tropomyosin (TM) increases significantly (13). Structural analysis has revealed that Tmod contains two domains, the $\mathrm{N}$-terminal domain and the $\mathrm{C}$-terminal domain $(13,14$, $16,19,21)$. The $\mathrm{N}$-terminal domain is responsible for binding to $\mathrm{TM}$ and the $\mathrm{C}$-terminal domain binds $\mathrm{F}$-actin. The latter domain is slightly bent by $40^{\circ}$ relative to the first domain (14). The structures of these two domains indicate that the N-terminal domain is most likely elongated and/or flexible and the C-terminal domain is most likely compact 
and tightly folded (19). Proteolysis experiments have helped forge a hypothesis in which the $\mathrm{N}$-terminal domain was much more susceptible to proteolysis than the $\mathrm{C}$-terminal domain $(19,21)$. Interestingly, it has been further hypothesized that Tmod's interaction with the F-actin/TM complex may only involve binding of Tmod to TM. The ability of Tmod to inhibit gain or loss of actin monomers may be due to steric hindrance. Since the calculated stoichiometry for Tmod to F-actin is 1.2-1.6, there can be up to two Tmod molecules capable of binding to TM at the pointed-ends of F-actin. The extra Tmod molecule helps to further the steric hindrance of polymerization $(14,28)$. Conversely, it has been reported that Tmod is capable of binding to TM-free F-actin and inhibiting polymerization $(14,19,32)$. This indicates the possibility of a direct, although weaker, interaction between Tmod with F-actin.

Tmod's interaction with TM is versatile. There are 16 known isoforms of TM generated from different genes and alternative splicing (29). Different isoforms of Tmod have been known to contain more than one region that can bind to TM. For example, Tmod1 has two distinct regions that can bind TM. The first region between residues 6-94 can bind TM in skeletal muscle. The second region, between residues $90-184$ is important for binding TM in erythrocytes or other non-muscle cells (13).

The N-terminal domain of Tmod binds to the N-terminus end of TM. Moreover, the first 14-18 amino acids of TM are sufficient to bind to Tmod (20). However, any modifications to the $\mathrm{N}$-terminus of TM such as the removal of the $\mathrm{N}$-terminal acetyl group or a mutation of certain amino acids at the end of TM will inhibit binding (16). The beginning amino acids of TM form a coiled coil secondary structure that is required 
for binding. This contributes to significant structural changes that occur between Tmod and TM upon binding (21). Furthermore, the isotype of TM found in the cell will dictate the affinity for which a specific isotype of Tmod will bind (16).

The critical concentration of actin depends on the affinity between actin monomers and the filament. Moreover, the likelihood of adding another G-actin monomer to the pointed-end of F-actin decreases when the phosphate group of an actin monomer on the pointed-end is removed. Bound Tmod can give F-actin more time for this slow phosphate-liberating reaction to occur. As more filaments lose phosphate groups, the affinity will decrease and consequently, the critical concentration will be raised. One might expect that since Tmod is not capping all the ends of F-actin simultaneously, there will always be exposed pointed-ends of actin that can maintain the critical concentration. However, due to the relative low affinity of Tmod for capping the pointed-ends of F-actin, Tmod is able to provide a critical role in decreasing the affinity of F-actin for more monomers at the slow growing ends (32). Tmod's low affinity allows it to bind effectively all the ends by moving from one filament to another and binding long enough to allow the phosphate groups to dissociate before another G-actin can be added. Studies using TM-free F-actin have demonstrated this effect, however in the presence of TM, the high affinity binding of Tmod to TM/actin does not affect the critical concentration as significantly $(31,32)$. Tmod's higher affinity for TM/F-actin does not allow it to move from one pointed-end to another as freely. Conversely, if the concentration of Tmod is increased, the critical concentration will rise, which shows how the natural occurrence of growing strands of F-actin in the cell will create a scenario that 
is described above. As actin molecules are added, TM cannot be incorporated into the molecule until enough actin molecules are present to bind the whole TM filament. During this time the critical concentration will rise as Tmod weak affinity for the slow growing ends allows it to weakly bind all the pointed-ends by quickly moving from one pointed-end to another $(31,32)$.

\section{Leiomodin}

More recently, another group of proteins have been implicated to be members of the tropomodulin family and were initially identified as the $64 \mathrm{kD}$ human autoantigen D1 (4). This novel protein was originally identified during screening of a thyroid cDNA library (8). The $64 \mathrm{kD}$ human autoantigen D1 was renamed smooth muscle leiomodin (SM-Lmod) due to its high expression in smooth muscle tissue (5). SM-Lmod is also expressed in a variety of tissue that contains smooth muscle based on dot blot analysis and is expressed in extraocular and slow striated muscle fibers $(4,5)$. Additionally, a second isoform of leiomodin has been named cardiac leiomodin (C-Lmod) as it is highly expressed in cardiac tissue. Both isoforms of Lmod contain a region between 85 to 305 amino acids, which is hypothesized to contain the isoform specific function of the two proteins due to their differences in length and pI's (5). Moreover, both of these isoforms contain considerable homology to the related tropomodulin sequences. Both Lmods contain a majority of the $\mathrm{N}$-terminal sequence found in Tmods that is important for TM binding. When the SM-Lmod protein was aligned to Tmod1, SM-Lmod began at amino acid 27 of Tmod1. Studies of Tmod1 missing the first 34 amino acids have shown to 
relinquish non-muscle TM binding. However, a study by Conley (3) showed that the truncate form of SM-Lmod was able to bind skeletal TM and not brain TM. This may indicate that the first 27 amino acids are not required for binding TM and TM isoforms in Tmods. Moreover, this study is consistent with the sequence of Lmod since this protein does not contain the sequence of Tmods required for binding non-muscle TM. Additionally, support has been made for SM-Lmod's ability to bind muscle TM through centrifugation studies implicating the presence of SM-Lmod in the Triton-insoluble cytoskeleton along with TM (3).

It is also hypothesized that Lmods are functionally capable of binding to actin since SM-Lmod has been shown to contain the sequence found in the C-terminus domain in Tmod, which is required for actin binding. Published studies showing actin binding of SM-Lmod in vitro still remain inconclusive (3). However, unpublished data support binding SM-Lmod for actin (S. Winfree and C. Conley, personal communication, NASA Ames Research Center, Mountain View, CA). The fact that Lmods contain considerable homology to Tmods and are capable of binding to muscle TM provide strong support for their addition to the tropomodulin family of proteins.

Although the exact function of Lmods remains to be explained definitively, it is believed that Lmods may associate along actin filaments in the relaxed muscle and then either associate to the ends of actin or be "excluded from contraction bands" during contraction (3). Another possibility is that during contraction, Lmods may associate with other contractile elements (3). Antibody staining of SM-Lmod in muscle tissue 
comparing relaxed and hypercontracted states have lead to the formulation of these hypothesizes.

\section{Mechanical Stress on Smooth Muscle Cells}

Smooth muscle cells are highly differentiated cells. However, these cells are not limited in their ability to change phenotype based on environmental cues. For example, vascular smooth muscle cells in blood vessels may change their phenotype from a contractile to a proliferative state, which is characterized by an increase in growth rate, and a decrease in the expression of $\alpha$-actin and smooth muscle myosin (23). Recently, studies that look into the effects of stress on cultured smooth muscle cells have employed the use of flexible culture wells with silicone-elastomer bottoms that can stretch when a vacuum is applied. This technique has been used with vascular smooth muscle cells in an attempt to better understand the effects of increased pressure on vascular smooth muscle cell phenotype during cardiovascular disease (26). Nevertheless, little is known regarding the effects of mechanical stress on the differentiation of vascular smooth muscle cells (23). Studies comparing vascular smooth muscle cells under conditions of mechanical stress and non-stress have shown that stress promotes the expression of growth factors such as platelet-derived growth factor, which acts in an autocrine manner to increase DNA synthesis and the number of cells in culture (33). Another study showed that basic fibroblast growth factor production was stimulated in stressed cells (26). Additionally, cultured vascular smooth muscle cells were shown to express both collagen and non-collagen extracellular matrix proteins (27). Furthermore, cultured smooth 
muscle cells from the airway have shown that stressed cells express more myosin light chain kinase. Additionally, it was shown that these airway cells exhibit a faster rate of contraction and a greater extent of shortening when placed under mechanical stress (25).

Finally, attempts to look into the effects of mechanical stress on actin in cells have been relatively limited. However, one study successfully showed the effects of mechanical stress on actin. This study indicated that in skeletal myoblasts the expression of $\alpha$-actin decreased however in cardiac myocytes the expression of $\alpha$-actin increased (2). This leads to the belief that both cell-types utilize a different mechanism of actin regulation.

Overall, the extent to which mechanical stress has been used to help understand effects such as contractile or proliferative states on smooth muscle cells need to be further elucidated. It should also be noted that many of the effects seen in smooth muscles taken from one source of tissue might not exert the same phenotypical change as another source of smooth muscle cells. 


\section{MATERIAL AND METHODS}

\section{Primary Cell Culture}

Sprague-Dawley rats were euthanized via $\mathrm{CO}_{2}$ narcosis and cervical dislocation. Tissue strips were teased away from the lower half of the stomach using sharp-sharp fine thumb forceps placed in PBS. Tissue strips were minced into fine pieces with scissors and incubated in $0.5 \mathrm{mg} / \mathrm{mL}$ collagenase (Type IA-S, C5894, Sigma-Aldrich 3050 Spruce St., St. Louis, MO 63103) mixed in phosphate buffered saline (P5368, Sigma-Aldrich 3050 Spruce St., St. Louis, MO 63103) at $37^{\circ} \mathrm{C}$ for 30 minutes. Next, cells and minced tissue strips were resuspended in Dulbecco's Modified Eagle's Medium (D5796, SigmaAldrich 3050 Spruce St., St. Louis, MO 63103) containing 10\% fetal bovine serum (F2442, Sigma-Aldrich 3050 Spruce St., St. Louis, MO 63103). Cells were then resuspended in DMEM containing 5\% FBS and penicillin-streptomycin. Cells were then plated onto 6-well Flex 1 cell culture plates (Flexcell International, 437 Dimmocks Mill Road, Hillsborough, NC 27278) containing a type I collagen coating. Pieces of the tissue from the collagenase incubation were placed in every well to allow more cells to migrate out from the tissue by explantation. Cells were fed with DMEM and 10\% FBS every three days and the tissue was discarded after six days.

\section{Cell Strain and Experimental Protocol}

Cells grown on the 6-well Flex 1 cell culture plates were then placed in a Flexcell culture system (Model: FX-4000T, Flexcell International, 437 Dimmocks Mill Road, Hillsborough, NC 27278). On day six cells were strained at a rate of 3 cycles per minute 
for duration of 10 seconds strained and 10 seconds relaxed. The strain exerted on the cells during the straining phase ranged from $6-8$ percent stretch. Membranes were removed 2 days, 4 days, 6 days, and 8 days after the start of straining for either staining, SDS-PAGE or western blotting.

\section{Cellular Immunostaining}

To stain the cells, the media was aspirated from the wells and the membranes were removed from the Flex 1 plates. These membranes were washed twice at room temperature with PBS and fixed with 3.6\% formaldehyde for 15 minutes, rinsed once with PBS and permeablized with 0.1\% Triton X-100 (234729, Sigma-Aldrich 3050 Spruce St., St. Louis, MO 63103) for 3-5 minutes. Membranes were then rinsed twice with PBS and blocked with $1 \%$ BSA in PBS for 30 minutes. Next cells were incubated with various primary antibodies specific for calponin (C2687, Sigma-Aldrich 3050 Spruce St., St. Louis, MO 63103), $\alpha$-actinin (A5044, Sigma-Aldrich 3050 Spruce St., St. Louis, MO 63103) or tropomodulin / leiomodin and were incubated overnight. The tropomodulin/leiomodin antibodies were obtained from Dr. Catharine Conley (NASAAMES). The three antibodies were diluted to $1 / 10,000,1 / 8,000$, and $30 \mathrm{ug} / \mathrm{mL}$, respectively. This mixture also contained 1\% BSA (A8531, Sigma-Aldrich 3050 Spruce St., St. Louis, MO 63103). The cells were washed three times in PBS for ten minutes each. A secondary antibody specific for each respective primary antibody (Molecular Probes/Invitrogen, 1600 Faraday Avenue, Carlsbad, California 92008) was incubated for 1 hour at a dilution of $1 / 1,000$. This mixture also contained $1 \%$ BSA and cells stained for 
actin contained a 1/40 dilution of Alexa fluor phalloidin (Molecular Probes/Invitrogen, 1600 Faraday Avenue, Carlsbad, California 92008). Cells were then washed three times for 10 minutes. Finally, the lips of the membranes were removed and the cells were mounted in a 1:1 ratio of glycerol and PBS. All washes and incubations were at room temperature. Cells were viewed with an epi-fluorescent microscope (Accu-Scope 316 epi-fluorescent, Olympus).

\section{Calponin Expression Quantitation}

Cells were cultured and stained as previously mentioned. Cells were also stained with Hoechst (34580, Molecular Probes/Invitrogen, 1600 Faraday Avenue, Carlsbad, California 92008) for counting total cells. To quantitate the percentage of calponin expressing cells, six pictures were taken at 20X for each group (e.g., 2-day, strained). Pictures were taken at the edge only for strained cells. Both total cells and cells expressing high amounts of calponin were counted manually using Metamorph 6.0 software (Universal Imaging Corporation). Time course data for strained and nonstrained wells were graphed and analyzed. Cells expressing calponin at a relatively lower level compare to other cells and not in a distinct pattern consistent with its expected localization along actin filaments were excluded. Unhealthy wells containing less than 75 cells were not included. 


\section{Characterization of Smooth Muscle Cells and Actin in vitro}

Cells were cultured and stained for actin as described above. 6-day wells for strained and non-strained cells were observed. Figure 2 shows the location of the well where the three pictures were taken. The first picture was taken at the edge; the second picture was taken in the middle and third was taken in the center. Additionally, Figure 2 shows where multiple pictures were taken to display the continuous response of smooth muscle cells from the highest amount of mechanical strain (edge) to the least amount of mechanical strain (center).

\section{Western Blotting}

Membranes were removed from the Flex 1 plates and washed once with PBS. Samples for SDS-PAGE were prepared by adding $12 \mathrm{uL}$ of $85^{\circ} \mathrm{C}$ SDS loading buffer (50mM Tris $\mathrm{Cl} \mathrm{pH} 6.8,100 \mathrm{mM}$ dithiothreitol, $2 \%$ SDS, $0.1 \%$ bromophenol blue, $10 \%$ glycerol) to the membranes containing the cells. The loading buffer was then scraped into a plastic $50 \mathrm{uL}$ micro-centrifuge and boiled in a water bath at $100^{\circ} \mathrm{C}$ for ten minutes. Samples were then placed into a sonicator bath (Sonicator Ultrasonic Processor, Structure Probe, Inc. / SPI Supplies, 569 East Gay Street West Chester, PA 19380) for three minutes on the highest setting. Samples were frozen at $-20^{\circ} \mathrm{C}$ until all samples of the time course were obtained. Once all samples were obtained, they were again boiled for ten minutes for thawing and denaturing then centrifuged for 10 minutes at $10,000 \mathrm{G}$. An additional tissue sample was obtained by placing a strip of tissue from rat stomach into 
the SDS loading buffer, homogenizing it with a microcentrifuge pestle and subjecting it to the same conditions as the previous samples. Next, $4 \mathrm{uL}$ of each sample were loaded and run on NuPAGEß Novex 4-12\% Bis-Tris gels (Invitrogen, 1600 Faraday Avenue, Carlsbad, California 92008, 1600 Faraday Avenue, Carlsbad, California 92008) with 1X MES as the running buffer. Gels were stained with Coomassie Blue by microwaving on the lowest setting for 30 seconds and allowing the gel to sit on a shaker for 1 hour. Gels were destained (10\% acetic acid, $40 \%$ methanol) again by microwaving for 30 seconds, shaking at room temperature for 1 hour and placing the gel in deionized water overnight at $4^{\circ} \mathrm{C}$. The image was analyzed using ImageJ (National Institute of Health) to normalize the protein concentrations. The adjusted volumes were loaded onto the four gels. One gel was stained with Coomassie Blue and the other three gels were used to transfer the protein to a nitrocellulose filter $(.22 \mathrm{um})$. Blots were stained with Ponceau $\mathrm{S}$ to confirm total protein transfer and blocked overnight with PBS-T (.1\% Tween 20$)$ and 5\% nonfat milk protein source overnight at $4^{\circ} \mathrm{C}$ and washed for one minute with PBS-T. The three blots were probed with either anti-calponin (Sigma-Aldrich 3050 Spruce St., St. Louis, MO 63103), anti- $\alpha$-actinin (Sigma-Aldrich 3050 Spruce St., St. Louis, MO 63103) or a combination of three monoclonal antibodies specific for tropomodulin and leiomodin overnight at $4^{\circ} \mathrm{C}$. The dilutions or concentrations of the antibodies were $1 / 5,000,1 / 5,000$ and $30 \mathrm{ug} / \mathrm{mL}$, respectively. The blots were then washed once for 15 minutes and twice for 5 minutes in PBS-T. A HRP-linked secondary antibody (NXA931, Amersham Biosciences, 800 Centennial Ave., Piscataway NJ 08855) was incubated at room temperature for 1 hour at a dilution of $1 / 1,000$. The blots were washed once for 15 
minutes and twice for 5 minutes in PBS-T. Finally the detection reagents (NXA931, Amersham Biosciences, 800 Centennial Ave., Piscataway NJ 08855) were added to the blot and exposed to Polaroid film in a darkroom. Exposure time was optimized depending on protein concentration and receptor affinity.

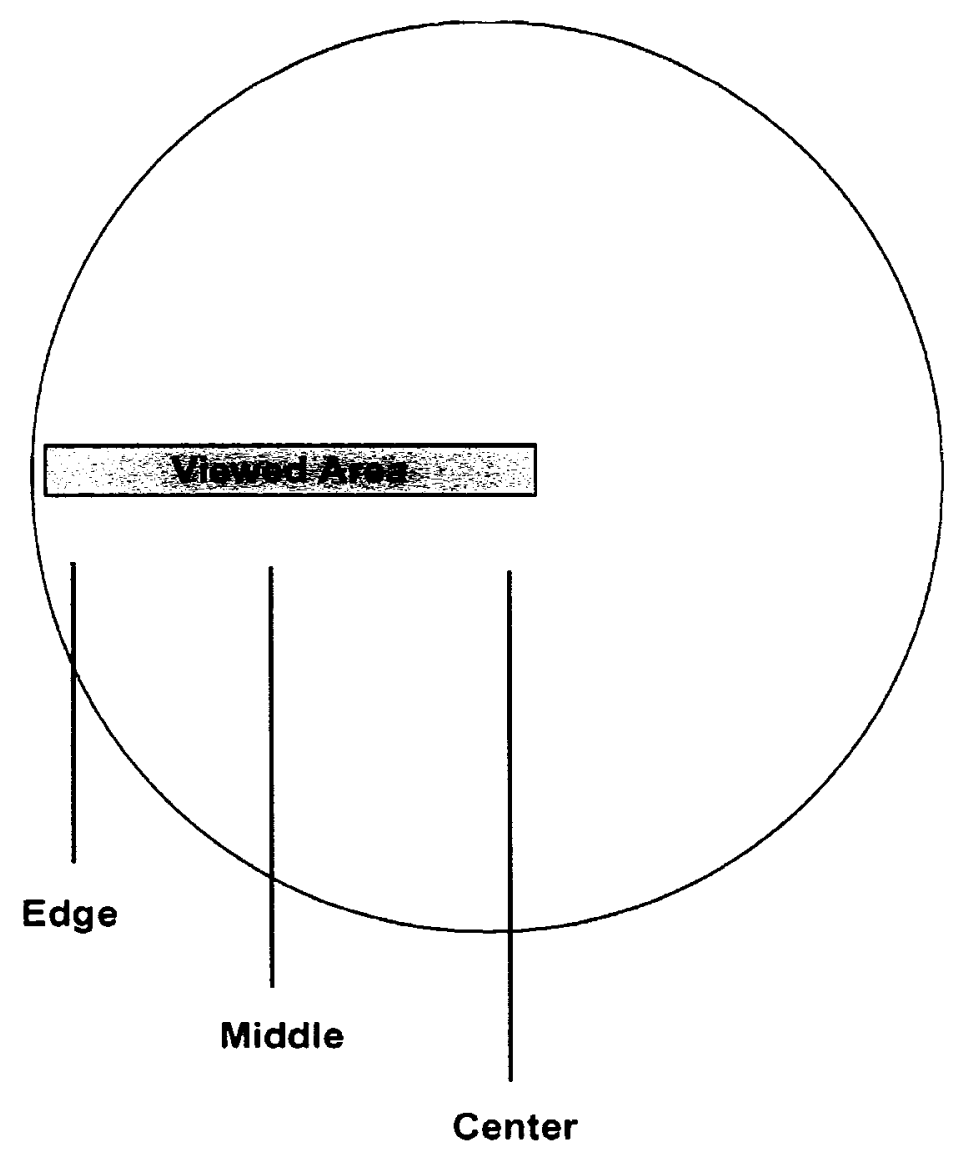

Fig. 2. Location where pictures were taken within strained and non-strained wells $(25 \mathrm{~mm})$. 


\section{RESULTS}

The following data depicted in Figures 3 though 12 and in Table 1 provide either support for or against each hypothesis stated in previous sections.

a)

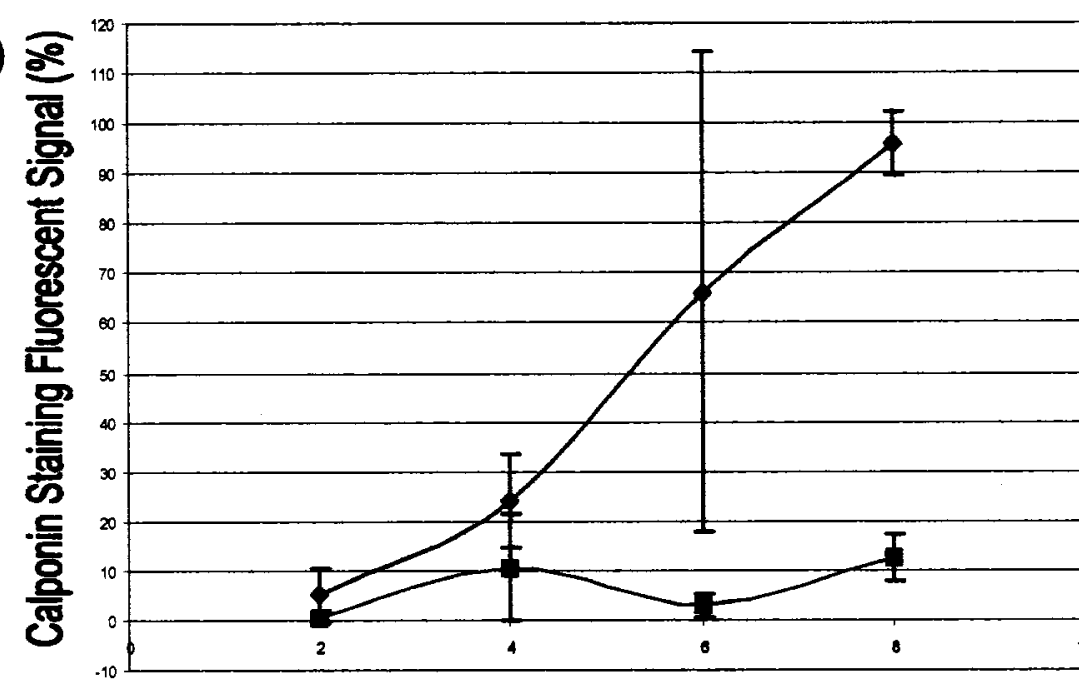

\section{$\rightarrow$ Strained \\ Non-strained}

Time Course (Days Post-Flexing)

b)

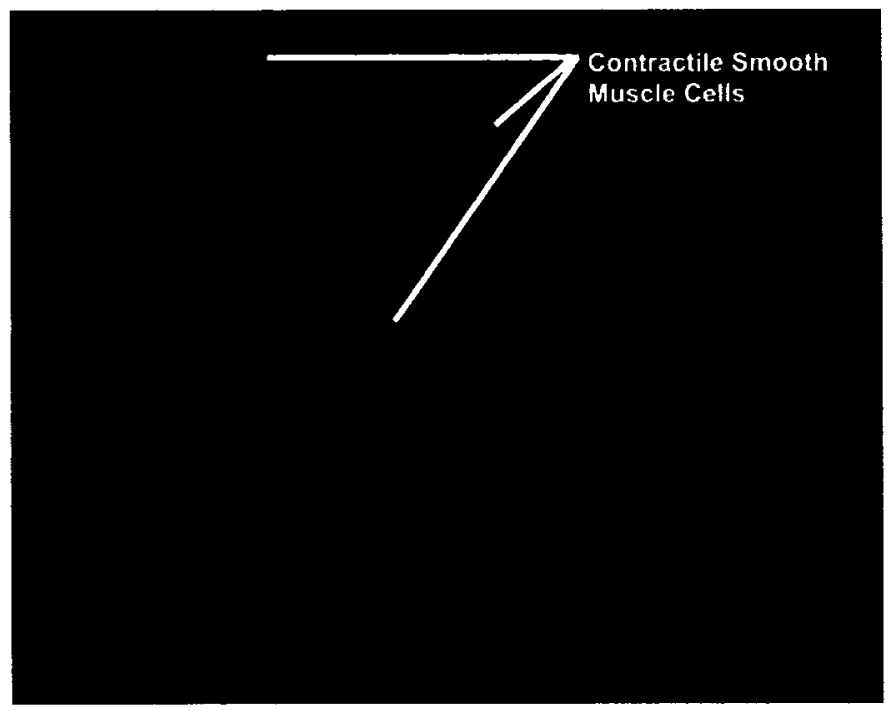

Fig. 3. a) Time course of strained and non-strained cells expressing calponin. b) Example of the photomicrograph used to count contractile cells with calponin staining. 


\section{Effect of Mechanical Strain on Smooth Muscle Cell Proliferation and Calponin Expression}

The results from Figure 3a of counting both strained and non-strained wells to compare the effects of mechanical strain on the number of smooth muscle cells in a contractile state indicate that as cells are aged, the percentage of cells with a high fluorescent signal of calponin increased in both strained and non-strained wells. Figure $3 \mathrm{~b}$ shows a photomicrograph of smooth muscle cells that are expressing a high calponin signal next to cells expressing relatively little calponin. This comparison was used to indicate contractile cells expressing high levels of calponin. Moreover, cells in the strained environment display higher percentages of calponin fluorescent signal compared to the non-strained cells at all days except for day 2 (Day $2:$ strained $=4.09 \% /$ nonstrained $=7.06 \%),($ Day $4:$ strained $=17.45 \% /$ non-strained $=8.22 \%),($ Day $6:$ strained $=$ $33.29 \% /$ non-strained $=5.71 \%),($ Day $8:$ strained $=95.75 \% /$ non-strained $=35.09 \%)$. This difference is first seen beginning at day 4 of mechanical strain and is consistently higher at day 6 and highest at day 8 . It should be noted that the number of replicates for each result varied from 2 to 6 depending on the number of healthy wells that contained a minimum of 75 cells. 


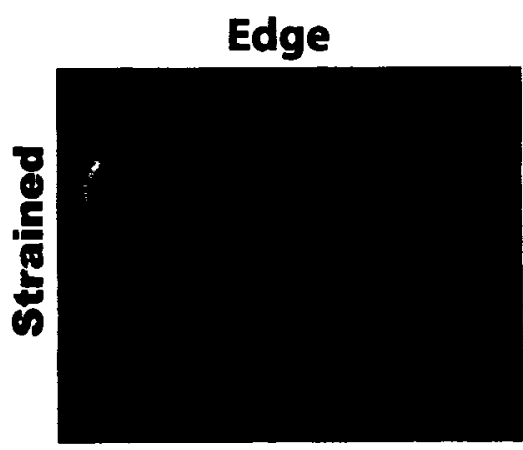

Middle

Center
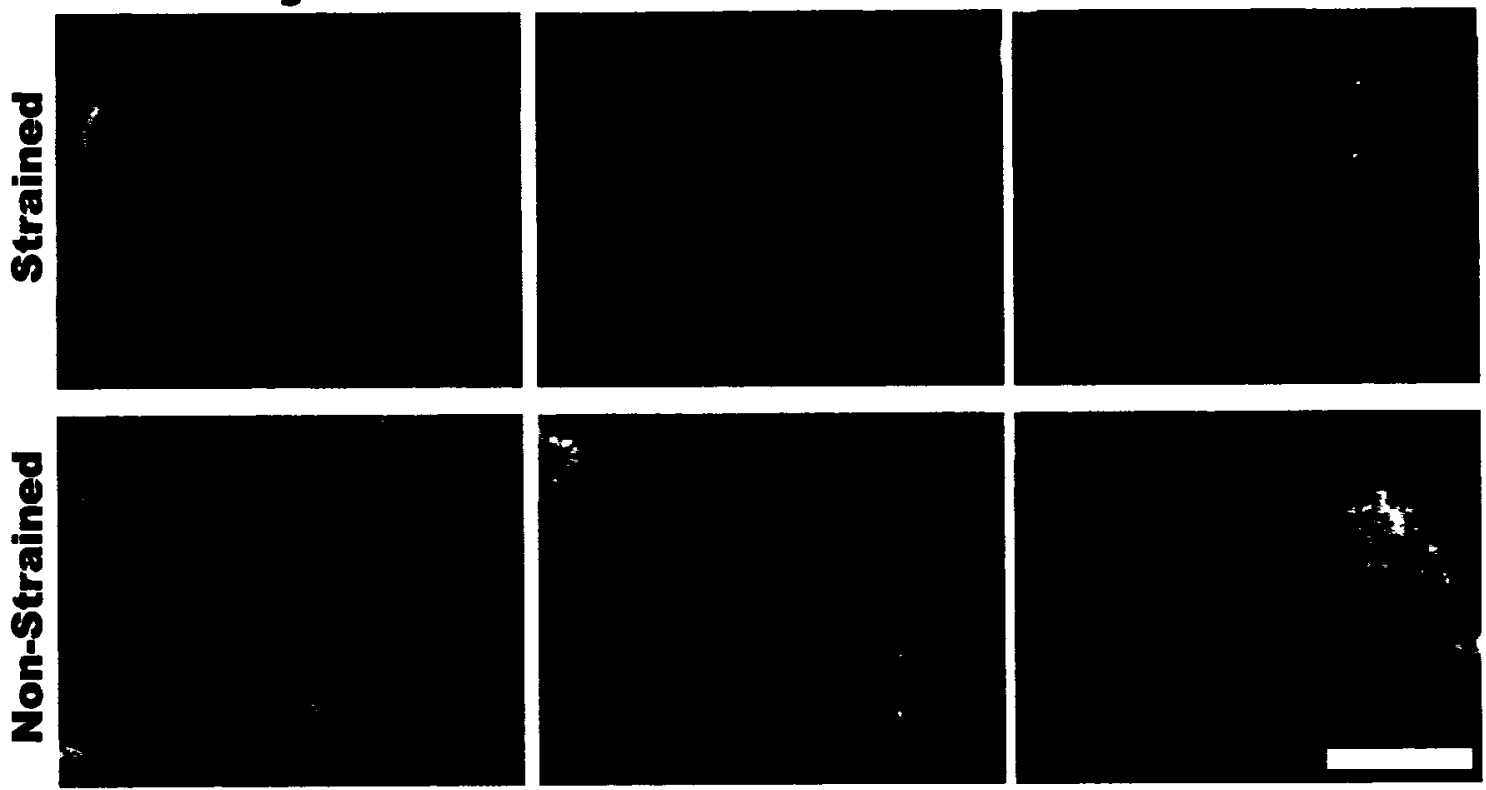

Fig. 4. Comparison of cells stained for actin (red) at six days after mechanical straining or in a non-strained environment. Pictures represent the edge, halfway between the edge and center (middle) and center of the wells. Cell nuclei stained blue with Hoechst. Bar, $50 \mu \mathrm{m}$. 


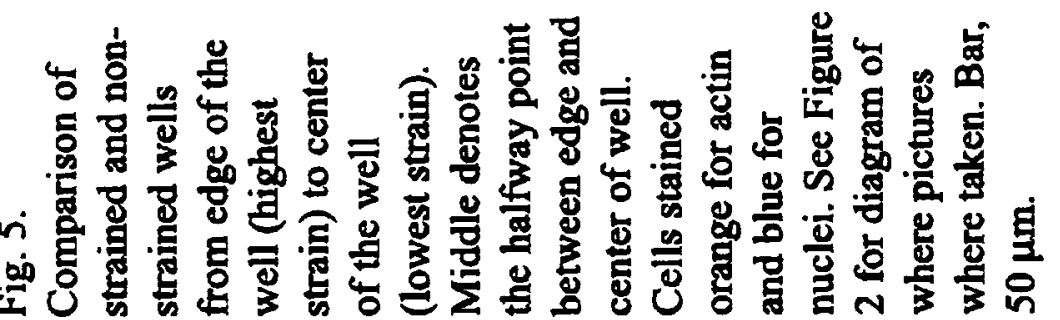
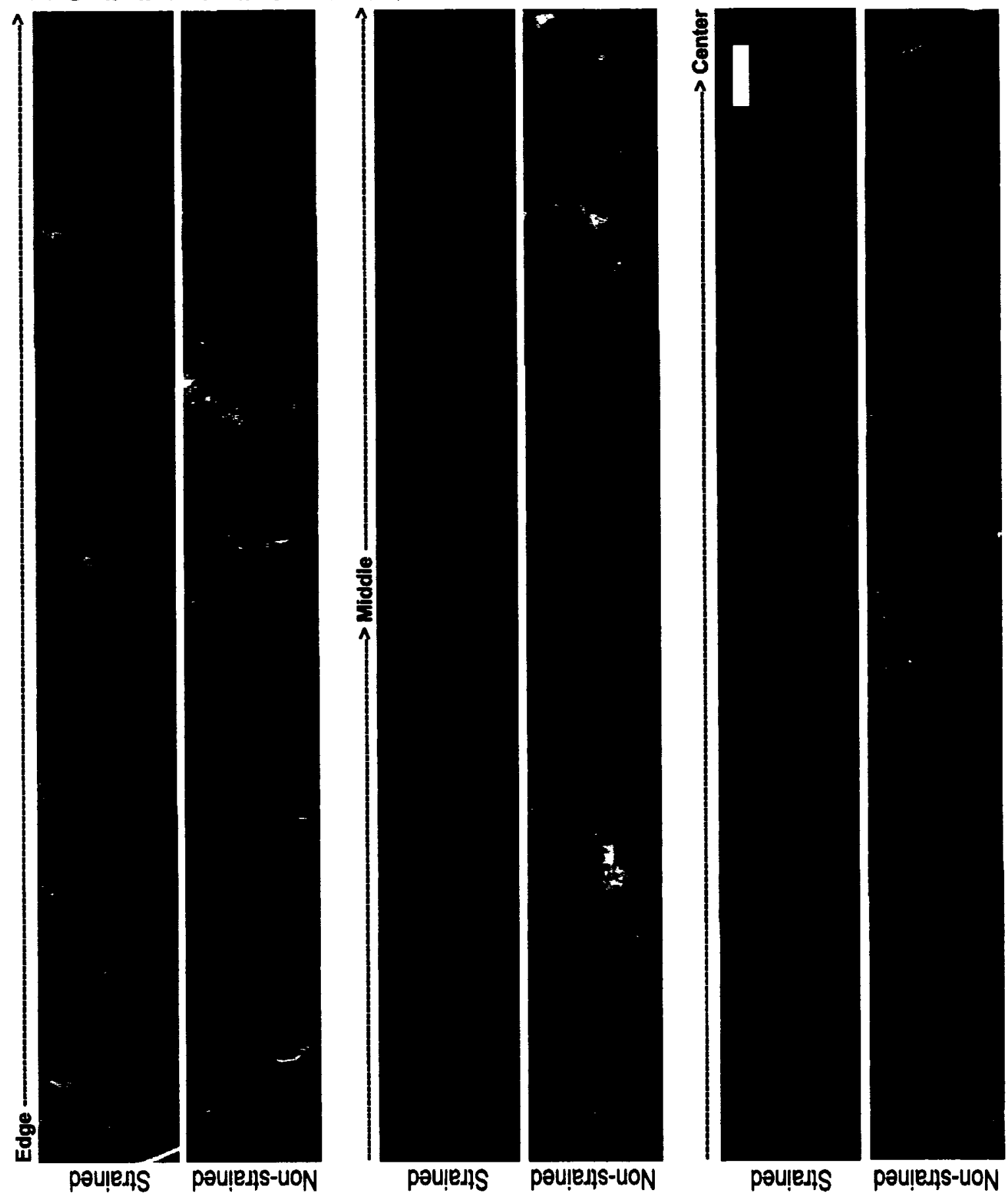


\section{Effect of Stress on Smooth Muscle Cells and Actin Orientation}

Figure 4 shows photomicrographs of cells grown for six days while being mechanically strained and cells that were placed under similar conditions but not strained. The first photomicrographs were taken at the edge of the wells (edge). The second picture was taken halfway between the edge and center of the well (middle). The third and final photomicrographs were taken at the center of the well (center). Photomicrographs were taken at these three areas to represent the response of cells in vitro on the Flex 1 membranes in culture. As expected, photomicrographs from the strained well display the different responses to mechanical strain from the edge of the well towards the center where mechanical strain is lowest. The mechanically strained picture at the edge shows cells and their actin filaments oriented perpendicular to the vector of stress placed on the cells. This finding indicates that the cells are responding to mechanical stress. Furthermore, comparison of photomicrographs from the edge between both strained and non-strained wells shows that cells undergoing mechanical stress have a significantly different morphology compared to non-strained cells. They also display a more smooth muscle-like shape, which is consistent with the increase of calponinexpressing cells as previously mentioned. Moreover, cells from the mechanically

strained wells towards the center of the well appear more like the non-strained cells. This may be due to the reported decrease of stress towards the center. Finally, shown in Figure 5, large groups of cells from this well were observed to display orientation perpendicular to other cells in the strained group toward the edge of the well. This was 
not seen on the non-strained group. This observation is a possible effect that may be unique to gastric smooth muscle cells in culture since tissue gastric smooth muscle is found in both the circular layer and the longitudinal layer, which are perpendicular to one another. 

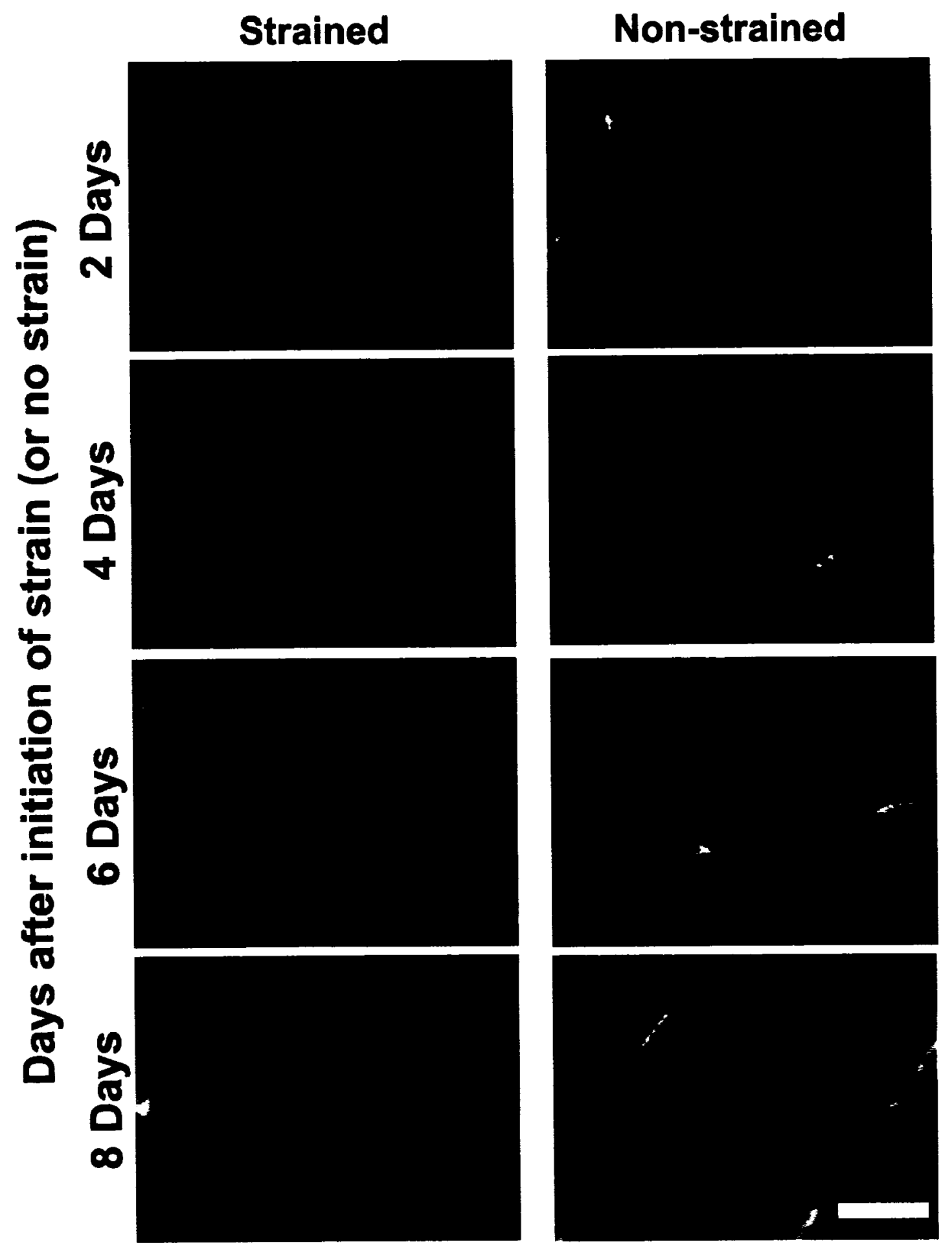

Fig. 6. Staining of cells for $\alpha$-actinin (red) and actin (green). Cells shown are representing the two-day through eight-day of both strained and non-strained wells. Pictures are taken at the edge of the wells to represent highest strain or no strain. Cell nuclei stained blue with Hoechst. Bar, $10 \mu \mathrm{m}$. 


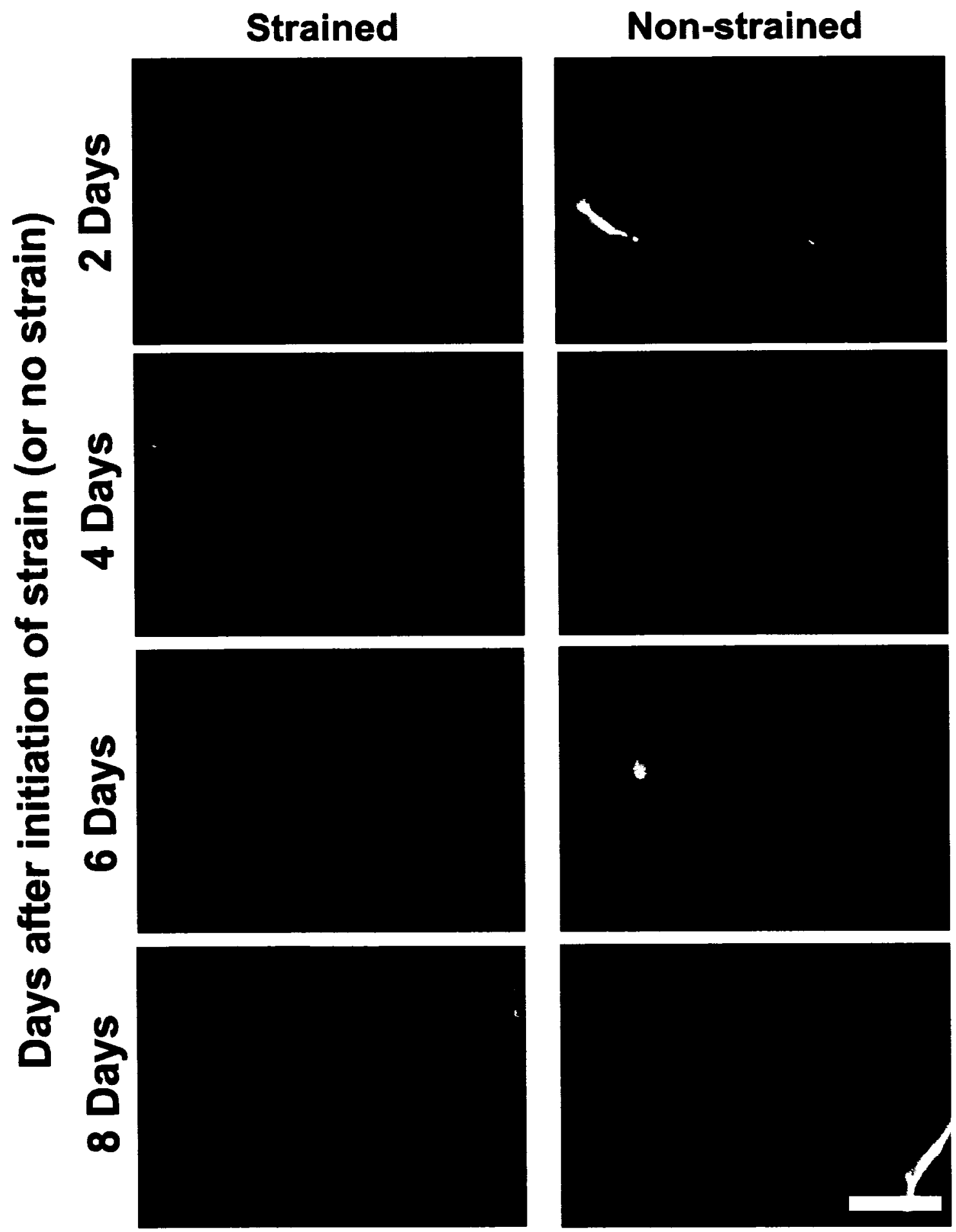

Fig. 7. Staining of cells for $\alpha$-actinin (red) and calponin (green). Cells shown are representing the two-day through eight-day of both strained and non-strained wells. Pictures are taken at the edge of the wells to represent highest strain or no strain. Cell nuclei stained blue with Hoechst. Bar, $10 \mu \mathrm{m}$. 


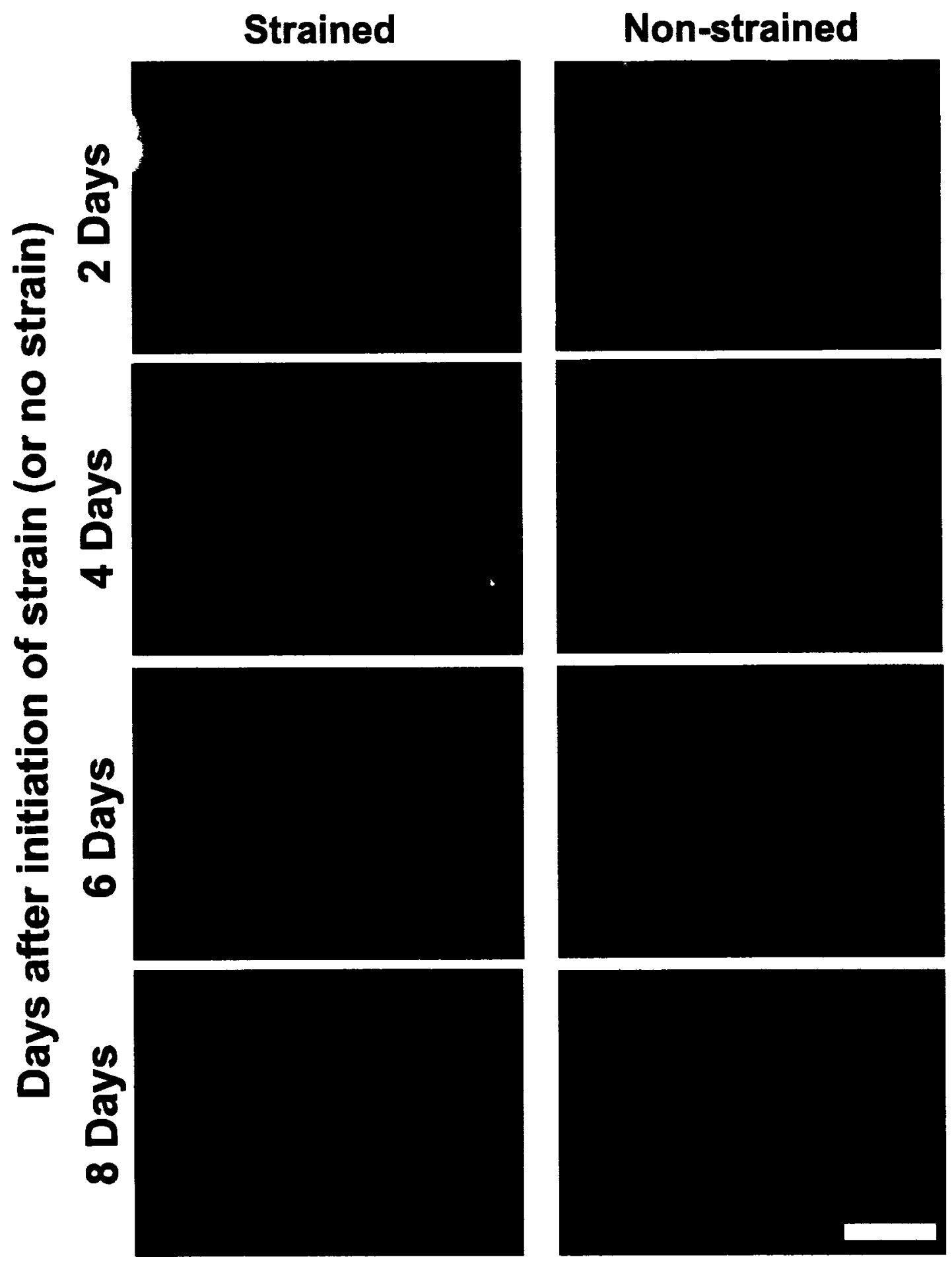

Fig. 8. Staining of cells for $\alpha$-actinin (red) and Tmod/Lmod (green). Cells shown are representing the two-day through eight-day of both strained and non-strained wells. Pictures are taken at the edge of the wells to represent highest strain or no strain. Cell nuclei stained blue with Hoechst. Bar, $10 \mu \mathrm{m}$. 


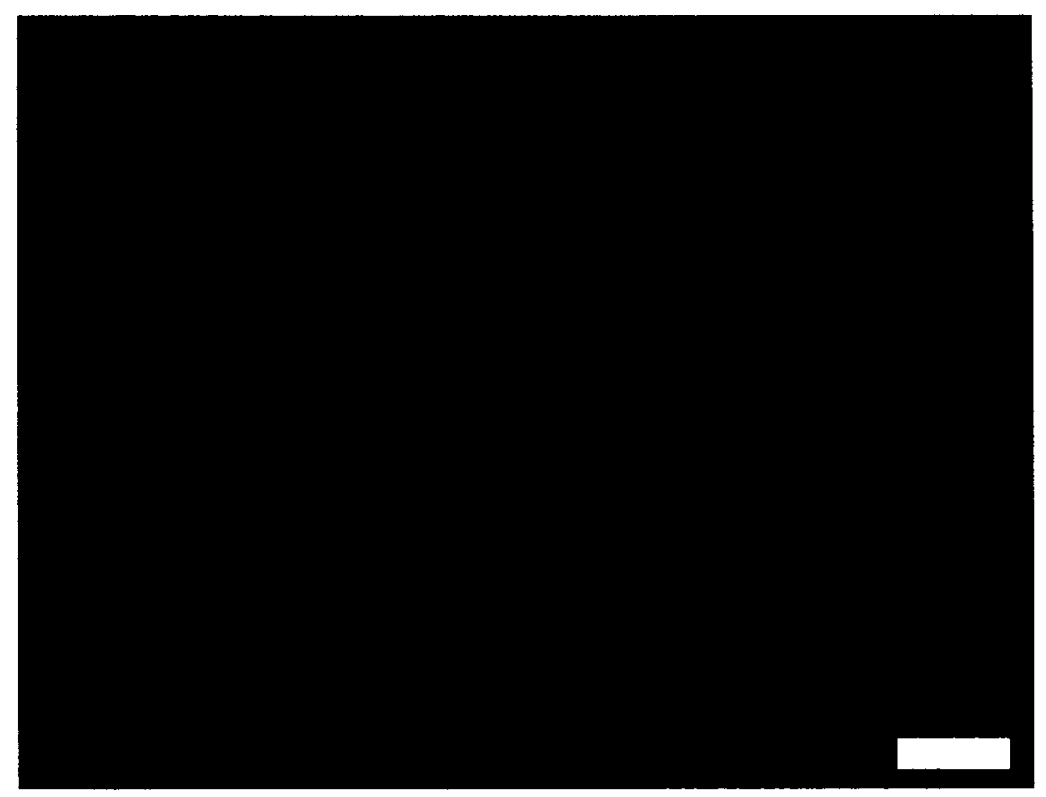

Fig. 9. Digital magnification of $\alpha$-actinin (red) and Tmod/Lmod (green) localization of eight-day sample after onset of strain. Bar, $1 \mu \mathrm{m}$.

\section{Visualization of Stained Cells at 100X Objective}

Cells that were stained for $\alpha$-actinin and either actin, calponin, or an antibody for Tmod and Lmod were compared to see if there were any differences among the localization of the proteins throughout the time course or between the mechanically strained and non-strained cells. Figure 6 shows cells stained for $\alpha$-actinin and actin. This supports the expected localization of $\alpha$-actinin along actin filaments as seen in tissue stained preparations done by Conley, 2001 (3). $\alpha$-actinin, shown in red, can be seen localized in similar regions to actin (green).

Figure 7 shows cells stained for $\alpha$-actinin and calponin. Subtle differences are seen in calponin localization between strained and non-strained cells and are more 
evident as time course progresses. Staining for calponin indicates localization predominantly around the nucleus in the mechanically strained group.

Figure 8 shows the localization of $\alpha$-actinin, Tmod, and Lmod. The antibody for Tmod and Lmod were combined, and the green signal indicates localization of both proteins.

The localization for Tmod/Lmod appears to be more perinuclear in the strained groups. Figure 9 shows the localization of $\alpha$-actinin and Tmod/Lmod at different locations. This supports previous work done by Conley, 2001 (3) which also showed that both $\alpha$-actinin and Tmod localized actin fibers at different locations. However, tissue, not cells, was used in that study. 
Average Relative Steady-State Protein Levels (no units)

\begin{tabular}{|c|c|c|c|c|c|c|}
\hline $\begin{array}{l}\text { Time Course \& } \\
\text { Strained / No } \\
\text { Strained }\end{array}$ & $\begin{array}{c}\text { Confluency } \\
(\%)\end{array}$ & Actin & Tmod & Lmod & Calponin & $\alpha$-actinin \\
\hline 0 Day & 22.5 & 1.0 & 26.0 & 6.4 & 2.3 & $1.0^{*}$ \\
\hline 2 Day - Strain & 60 & $1.9^{*}$ & $13.0^{*}$ & 2.1 & 4.3 & $8.2^{*}$ \\
\hline 2 Day - No Strain & 67.5 & $2.0^{*}$ & $13.8^{*}$ & 2.9 & 6.9 & $8.0^{*}$ \\
\hline 4 Day - Strain & 90 & 2.2 & 8.8 & 4.1 & 3.4 & $9.2^{*}$ \\
\hline 4 Day - No Strain & 87.5 & 2.4 & 8.2 & 4.3 & 5.4 & $11.2^{*}$ \\
\hline 6 Day - Strain & 97.5 & 2.2 & 4.6 & 2.4 & 13.5 & 6.1 \\
\hline 6 Day - No Strain & 80 & 2.0 & 5.0 & 2.2 & 12.3 & 7.6 \\
\hline 8 Day - Strain & 97.5 & 1.6 & 2.8 & 2.4 & 11.6 & 6.3 \\
\hline 8 Day - No Strain & 97.5 & 1.8 & 1.0 & 3.1 & 15.8 & 6.8 \\
\hline
\end{tabular}

Table 1. Quantitation of SDS-PAGE and western blotting for actin, Tmod, Lmod, calponin, and $\alpha$-actinin. ${ }^{*}$ Data indicates one replicate. All other data are averages from two replicates.

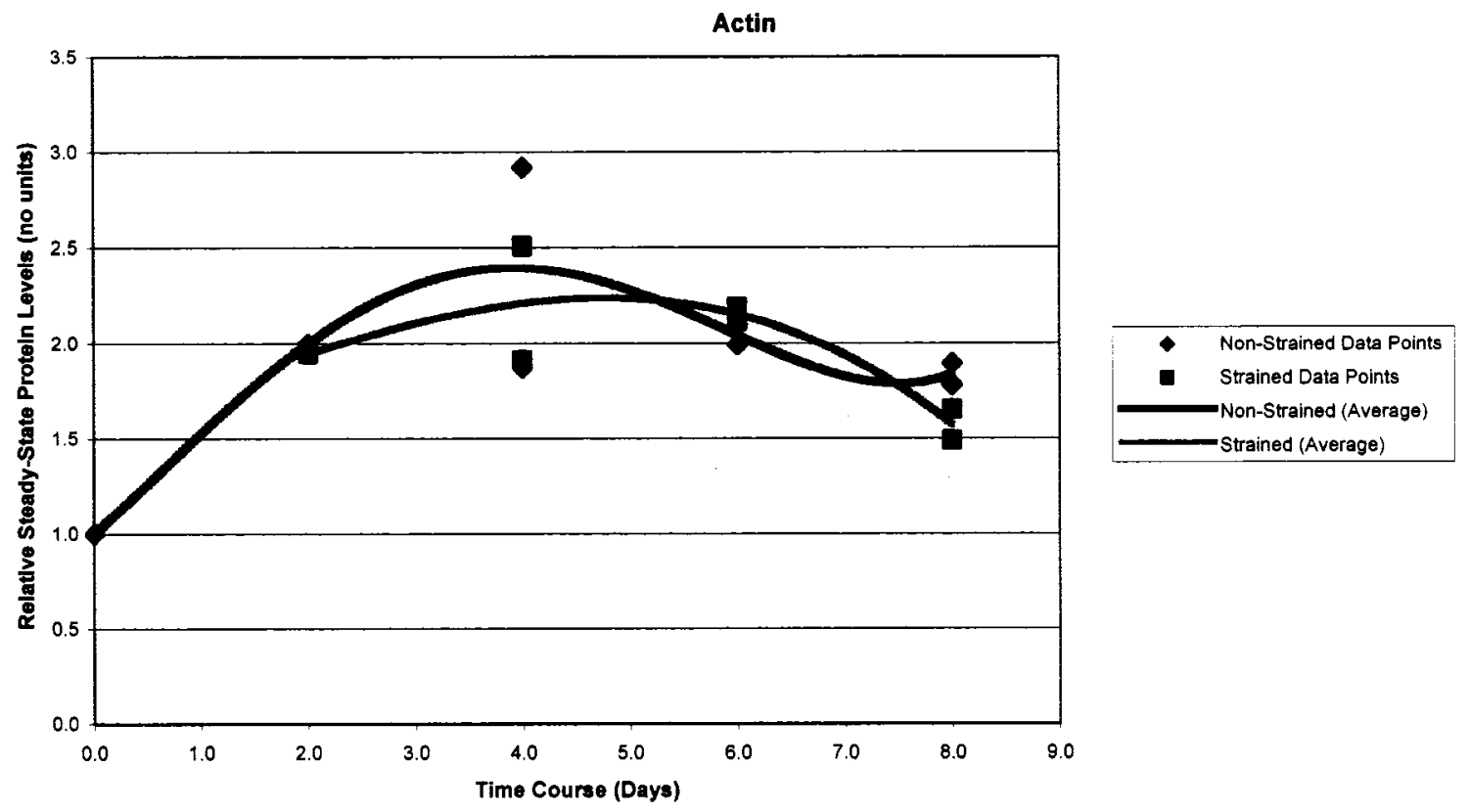

Fig. 10a. Graphical data (of Table 1) from quantitative western blots of actin. Each $\mathrm{Y}$-axis represents the relative number amount of protein and the $\mathrm{X}$-axis represents the time course for strained and non-strained cells. 


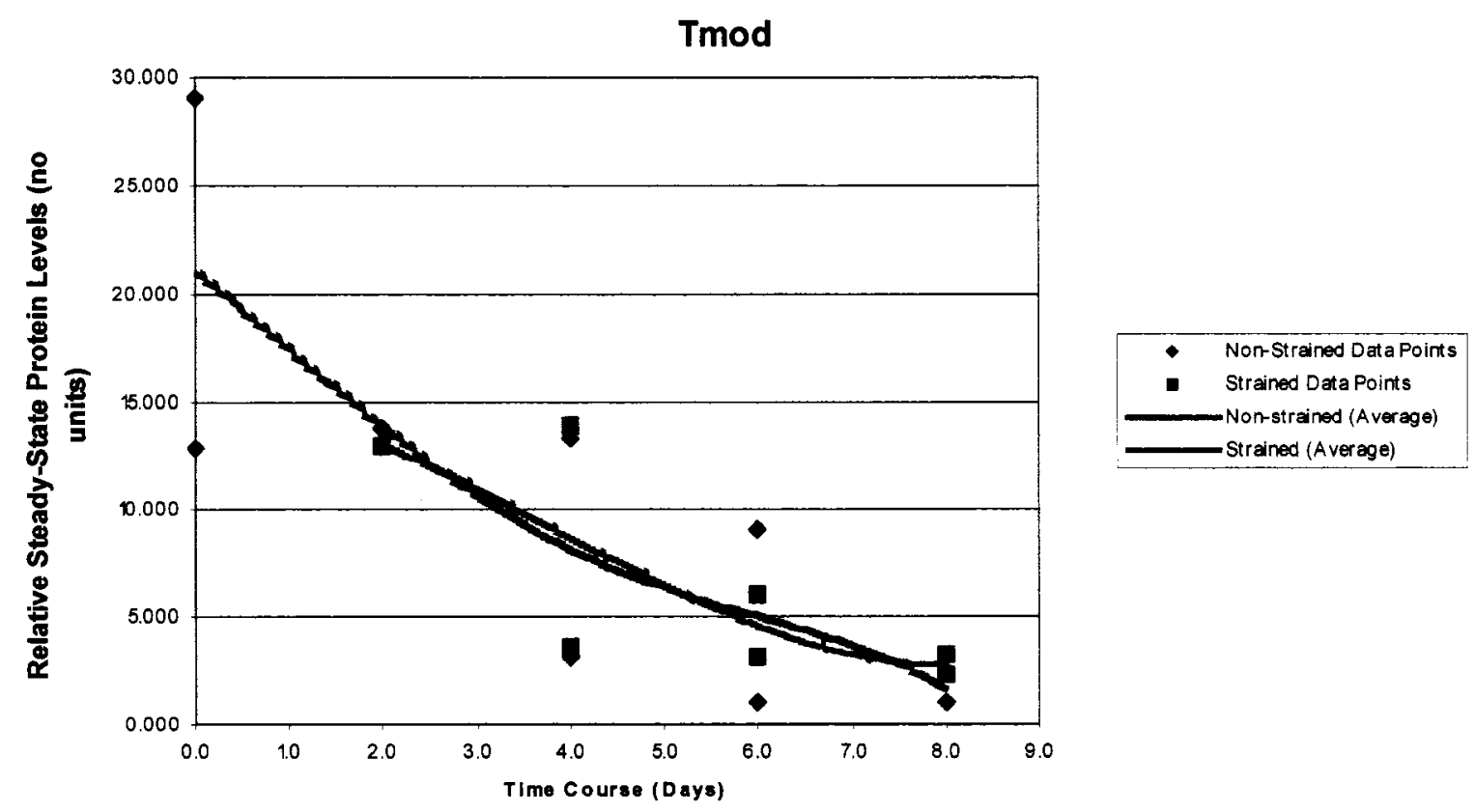

Fig. 10b. Graphical data (of Table 1) from quantitative western blots of Tmod. Each $\mathrm{Y}$-axis represents the relative number amount of protein and the $\mathrm{X}$-axis represents the time course for strained and non-strained cells.

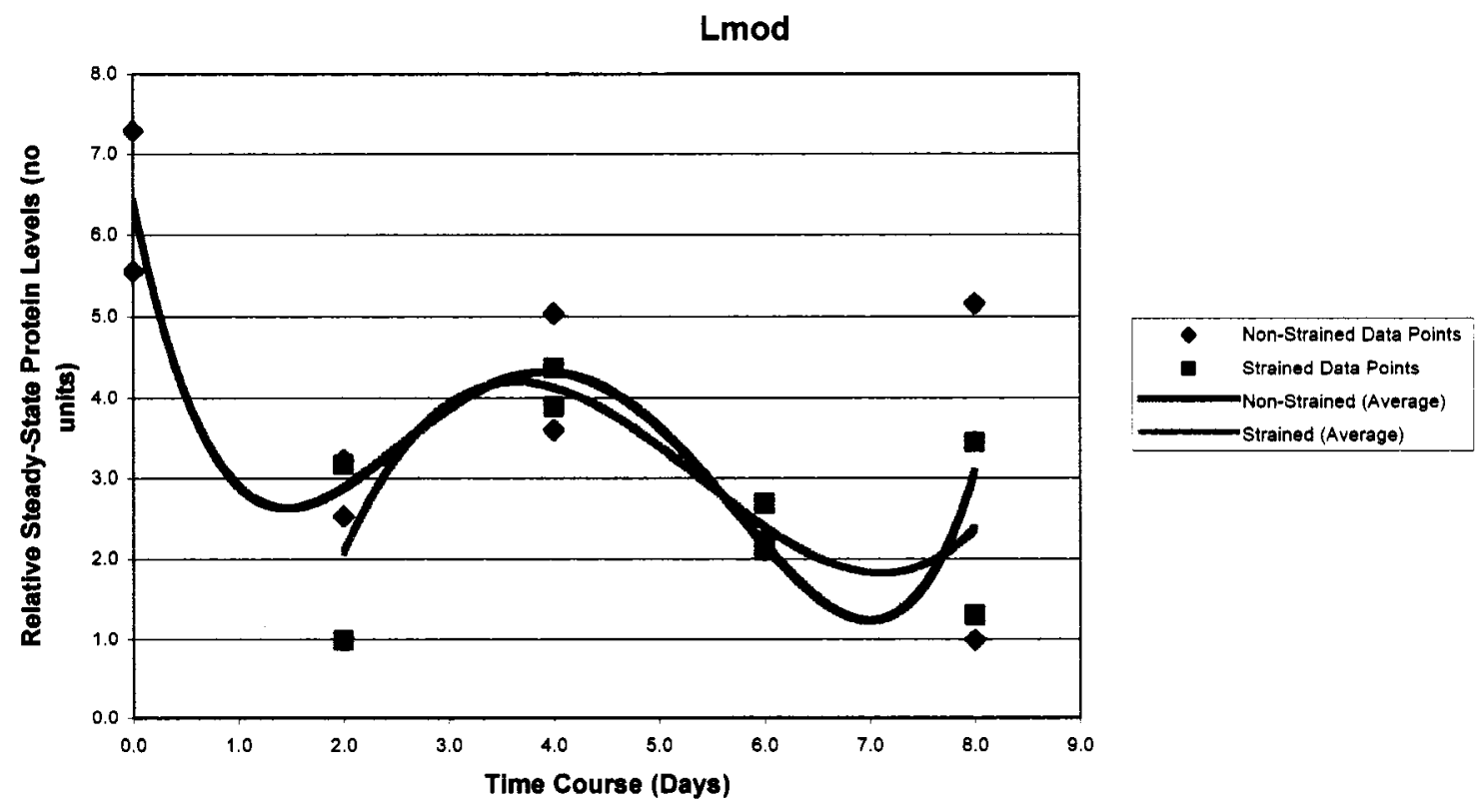

Fig. 10c. Graphical data (of Table 1) from quantitative western blots of Lmod. Each $\mathrm{Y}$-axis represents the relative number amount of protein and the $\mathrm{X}$-axis represents the time course for strained and non-strained cells. 

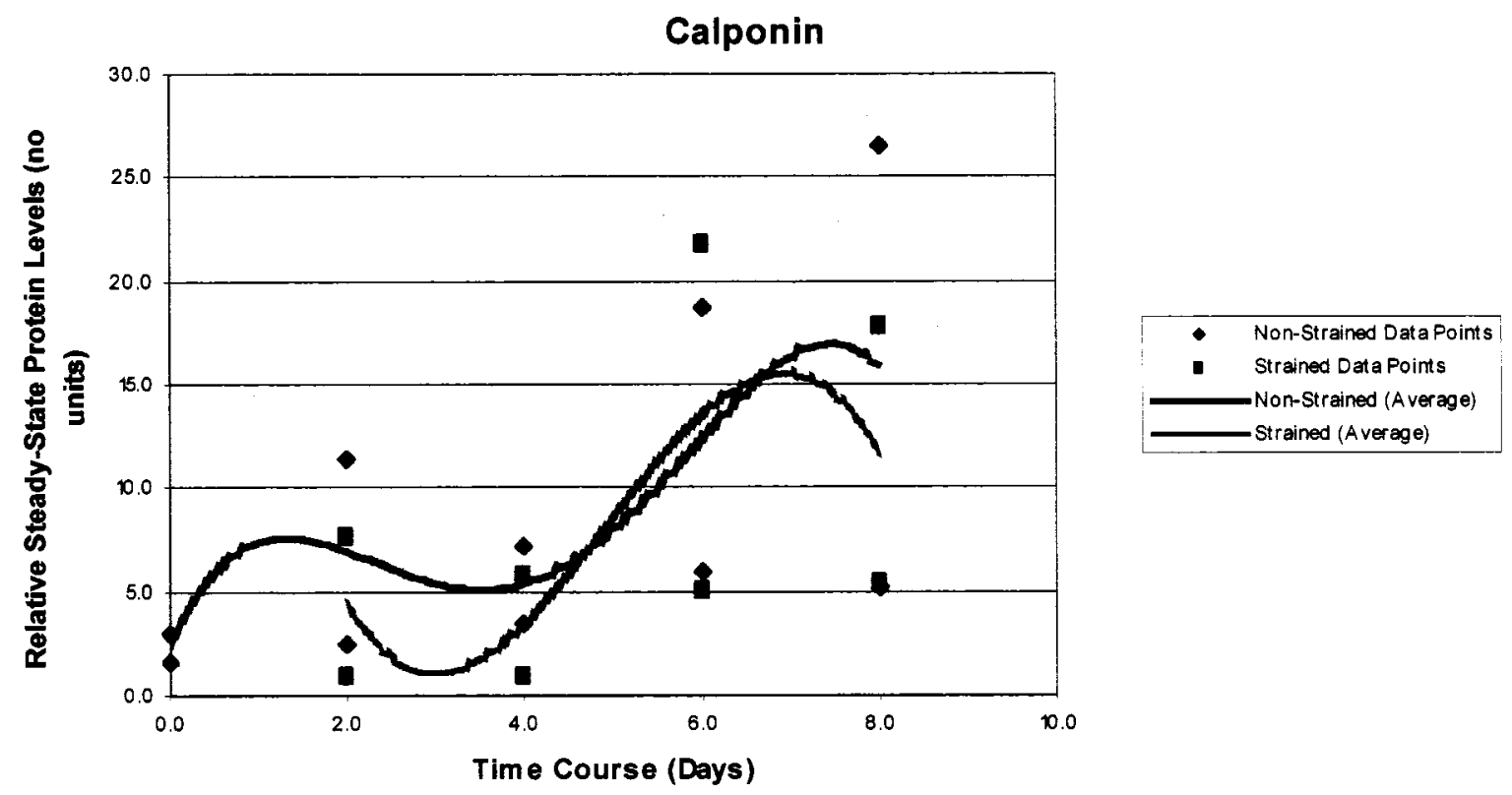

Fig. 10d. Graphical data (of Table 1) from quantitative western blots of calponin. Each Y-axis represents the relative number amount of protein and the $\mathrm{X}$-axis represents the time course for strained and non-strained cells.

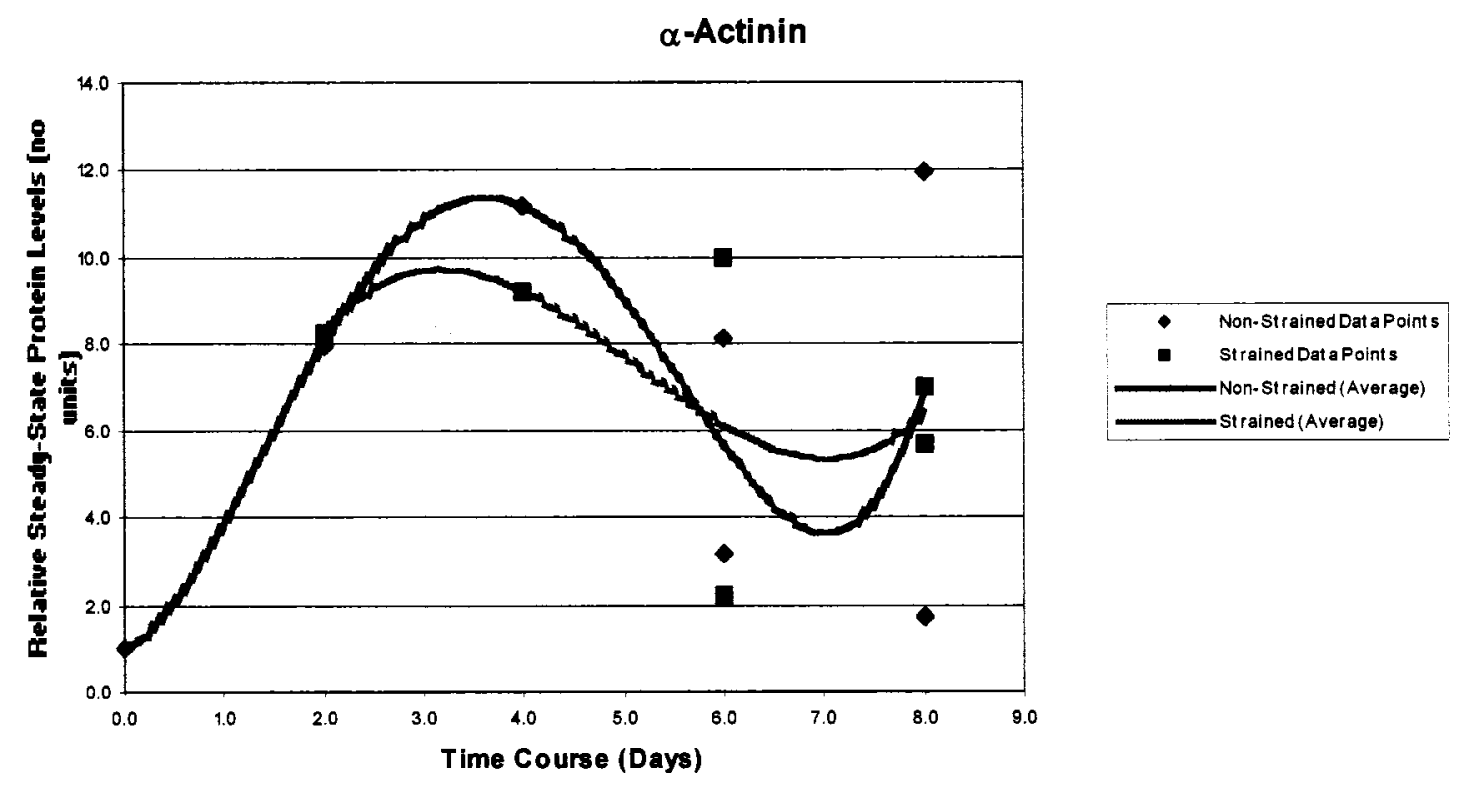

Fig. 10e. Graphical data (of Table 1) from quantitative western blots of $\alpha$ actinin. Each $Y$-axis represents the relative number amount of protein and the $\mathrm{X}$-axis represents the time course for strained and non-strained cells. 
a)

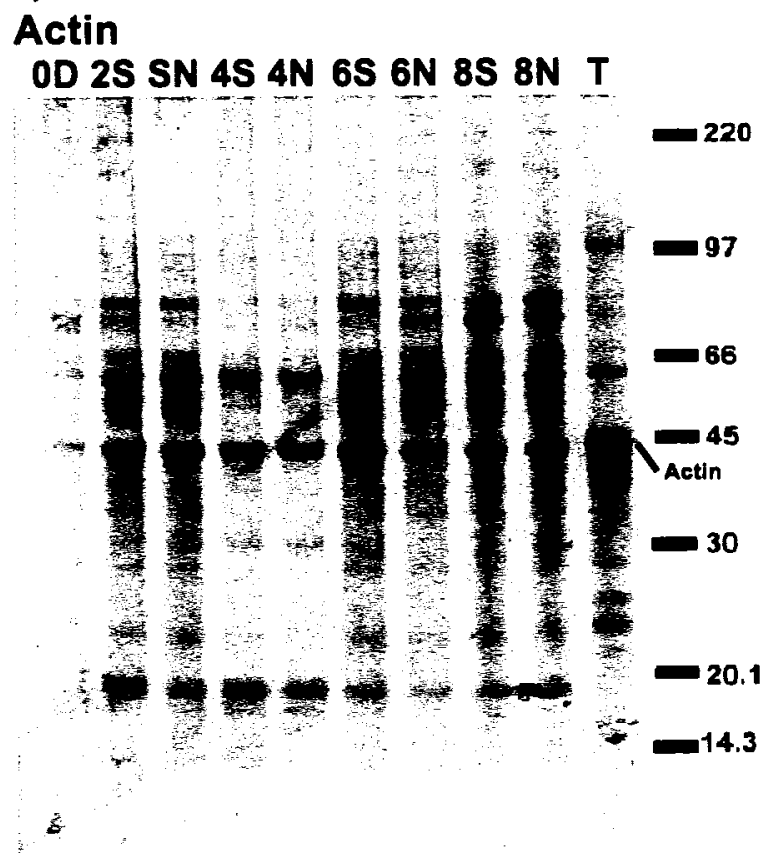

b)

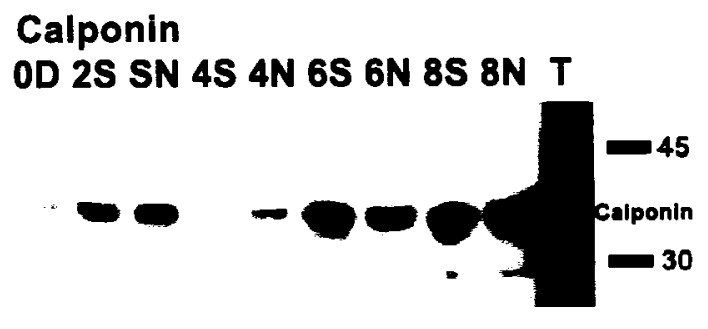

c)

$\alpha$-actinin

OD 2S SN 4S 4N 6S 6N 8S 8N T

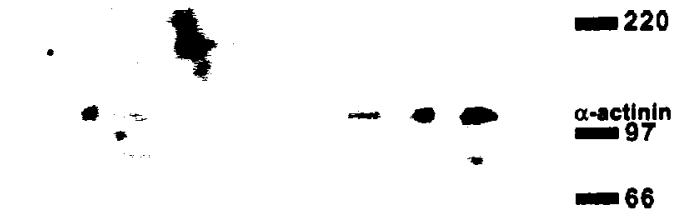

d)

Tmod / Lmod OD 2S SN 4S 4N 6S 6N 8S 8N T

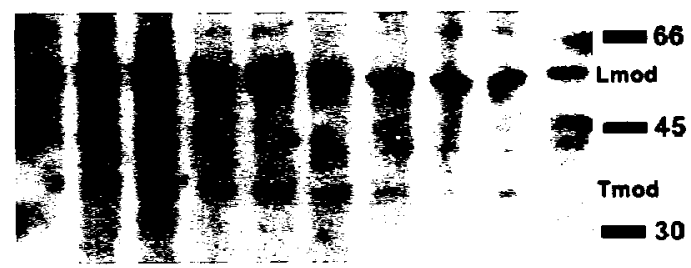

Fig. 11. a) SDS-PAGE after total protein normalization to quantitate relative amounts of actin. b) Western blot to quantitate calponin. c) Western blot to quantitate $\alpha$ actinin. d) Western blot to quantitate both Tmod and Lmod. Time course was for start of strain (0D), two days through eight days after strain (2S-8S) and two days through eight days in a non-strained environment $(2 \mathrm{~N}-8 \mathrm{~N})$. 
SDS-PAGE and Westerns Blotting of Actin, Tmod, Lmod, Calponin, and a-actinin

SDS-PAGE was used to quantitate actin. Western blots were used to quantitate Tmod, Lmod, calponin, and $\alpha$-actinin. Based on the results presented in Table 1, Figure 10, and Figure 11 the differences between strained and non-strained steady-state levels of all five proteins could not be identified. Additionally, no trends could be observed for the five proteins throughout the time course (see discussion for further explanation of these results). 

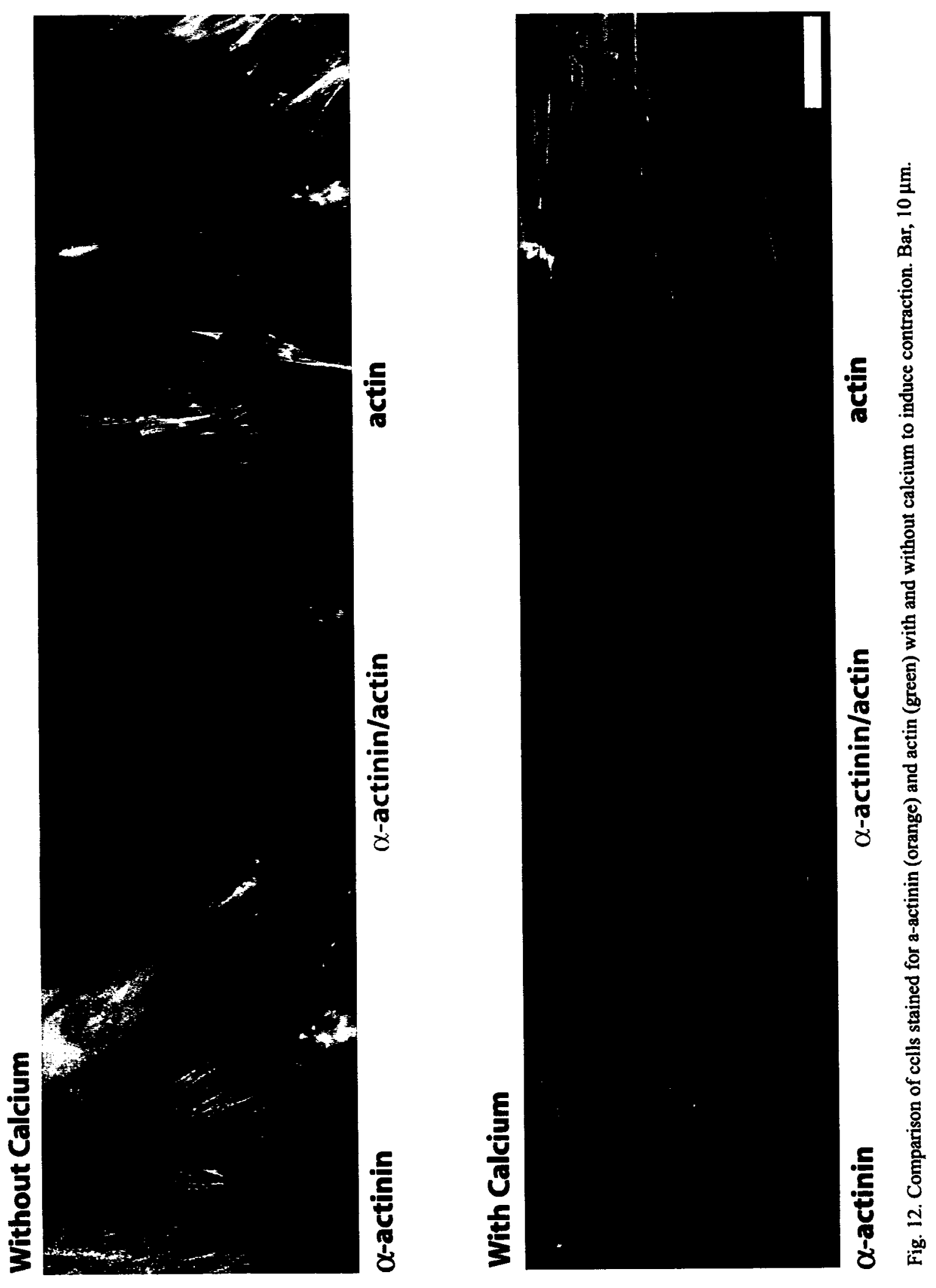


\section{Effect of Calcium on $\alpha$-actinin Localization}

Cells were stained for $\alpha$-actinin and actin and then treated with calcium to induce contraction or without calcium to maintain a non-contracted state. Based on the results (Fig. 12), the localization of $\alpha$-actinin was significantly different between cells induced to contract. The localization of $\alpha$-actinin is displayed in a more organized fashion in cells without calcium added prior to fixation. In cells with calcium added, the localization of $\alpha$-actinin is not present along the actin fibers. The dense bodies that contain $\alpha$-actinin are in larger clusters in the non-contracted cells. However, these dense bodies disperse when calcium is added. 


\section{DISCUSSION}

In this study, a new technique to examine the mechanisms of cultured smooth muscle was established. Previously, culture systems have used tissue from vascular, airway, and bladder sources. However, this study has demonstrated that gastric tissue can be a good source of smooth muscle cells for in vitro studies to elucidate G.I. smooth muscle function.

Cultured gastric smooth muscle is capable of responding to mechanical stress, which is evident from the differences in orientation of strained smooth muscle cells and their actin filaments compared to non-strained counterparts (see Fig. 4). Moreover, varying stress leads to different morphology and proliferation of these cells based on differences seen at various regions of strained wells (Fig. 5). Figure 5 also displays groups of smooth muscle cells that are aligned perpendicular to each other in the strained group only. This is observed between the edge and middle of the well where mechanical strain is highest, indicating a more representative model for contractile smooth muscle cells since gastric tissue contains smooth muscles in perpendicular orientation.

Previous studies have shown that mechanical stress increases the growth rate of cultured vascular smooth muscle cells (23). Another study showed that the increased growth rate of cultured vascular smooth muscle cells is mediated by an increase in platelet derived growth factor (33). However, it should be noted that the effect of mechanical stress to increase proliferation as shown in this study has been only observed qualitatively. More quantitative studies are needed to explain the effects of mechanical stress on gastric smooth muscle proliferation. 
Moreover, the issue of cells falling off the membrane under mechanical strain should also be considered. This could have contributed to loss of cells in the mechanically strained group that decreased the number of cells. To limit this issue, cells were allowed to grow for six days to adhere to the collagen-coated membrane before the onset of mechanical strain.

Our observations on the morphology of cultured smooth muscles cells suggest that non-strained cells may be in a more proliferative state while the strained cells are more likely to be in a contractile state. Again, studies that quantitate the growth rate of gastric smooth muscle cells would help resolve the question of how mechanical stress stimulates growth.

Mechanical stress induces a higher percentage of smooth muscle cells to enter a contractile state compared to non-stressed cells (Fig. 3). A smooth muscle cell in a contractile state is defined, for the purpose of this study, as a cell expressing relatively high levels of the calponin fluorescent signal. This increase in the calponin signal may be due to an increase in steady-state proteins levels of calponin or the reorganization of calponin in a contractile state. Calponin is believed to play a role in the regulation of smooth muscle cell contraction $(10,18)$. Again, this result indicates that a system that provides mechanical strain may provide a better model for the study of contractile smooth muscle cells.

Additionally, western blot data (Fig. 10, Fig. 11, and Table 1) was not able to show differences in the steady state levels of calponin between strained and non-strained smooth muscle cells. It was also not able to show differences between strained and non- 
strained cells in the steady-state protein levels of actin, $\alpha$-actinin, tropomodulin or leiomodin, which play important roles in contraction. This result may be due to the fact that protein levels were normalized based on total protein. Hence, if there were a greater expression of total protein in mechanically strained cells, the amount of specific protein (i.e. calponin, actin, $\alpha$-actinin, tropomodulin, and leiomodin) detected would be decreased. Another possibility is that our methods of detection were not sensitive enough to detect the subtle differences in steady-state protein levels between strained and nonstrained cells.

Moreover, data from westerns were obtained from two repeated experiments that gave similar results regarding the steady state levels of proteins from stressed and nonstressed cells. More repetitions of this experiment are required to statistically find differences. Also, more studies looking at the effects of mechanical stress on protein expression should be conducted with greater sensitivity to make a more definitive conclusion.

Figure 6 shows staining for $\alpha$-actinin and actin. $\alpha$-actinin localized along actin filaments can be seen from the staining of cultured cells. This meets our expectations, since studies have shown $\alpha$-actinin in smooth muscle tissue can be found at regions of dense bodies where barbed-ends of actin are anchored (3).

Figure 7 shows $\alpha$-actinin and calponin staining. It appears that calponin is predominantly perinuclear in the mechanically strained cells. The non-strained cells are a little more diffuse in calponin localization. The actual localization of calponin has been under debate. It has been stated that calponin can be found uniformly throughout the cell 
and also in certain regions of the smooth muscle cell (18). However, our study suggests the majority of calponin is more limited to perinuclear regions in a contractile state.

Staining of smooth muscle cells for $\alpha$-actinin and Tmod/Lmod is shown in Figure 8 and Figure 9. (It should be noted that a combination of monoclonal antibodies for Tmod was used. Based on western blot data, we believe that our combination antibody binds both Tmod and Lmod.) It is concluded that actin contains two distinct domains for its slow growing, pointed-ends and fast growing, barbed-ends. Moreover, these data support previous work done by Conley, 2001 (3). While it is known that the fast growing barbed-ends localized to dense bodies within the cell, further research with this system or another may provide greater understanding regarding the localization of the slow growing, pointed-ends in both a relaxed and contracted smooth muscle cell.

Additionally, this result supports the in vivo representation of smooth muscle in vitro; again providing reason to believe this system can serve as a useful tool for understanding smooth muscle function.

Finally, membranes that were hyper-contracted with the addition of calcium prior to fixing showed a distinct change in localization of $\alpha$-actinin compared to cells that were not contracted (Fig. 10). At this point, still little is known about the mechanisms that occur during contraction with actin remodeling. $\alpha$-actinin, which is found in dense bodies, is located in large clusters in the non-contracted smooth muscle cells. However, upon contraction, these dense bodies are more dispersed. This observation suggests that during contraction, $\alpha$-actinin migration along with actin fiber remodeling may be playing a crucial role in the process. This result should lead to further studies towards 
understanding how and where the two ends of actin filaments move during contraction and the role that regulatory proteins such as $\alpha$-actinin have.

In conclusion, the primary culture system described herein has provided a foundation for future studies on gastric smooth muscle contraction. Additionally, this system may help describe the function of proteins unique to smooth muscle such as calponin, tropomodulin, and leiomodin. An initial characterization of the culture system has been made and the effect of mechanical strain increasing the contractile apparatus of smooth muscle cells has been made. Future studies regarding the further characterization of this system may give way to important discoveries leading to understanding the molecular mechanisms of the smooth muscle cell. 


\section{REFERENCES}

1. Almenar-Queralt A, Lee A, Conley CA, Ribas de Pouplana L, and Fowler VM. Identification of a novel tropomodulin isoform, skeletal tropomodulin, that caps actin filament pointed-ends in fast skeletal muscle. J Biol Chem 274: 2846628475, 1999.

2. Carson JA, and Booth FW. Effect of serum and mechanical stretch on skeletal alpha-actin gene regulation in cultured primary muscle cells. Am J Physiol 275: C1438-C1448, 1998.

3. Conley CA. Leiomodin and tropomodulin in smooth muscle. Am J Physiol Cell Physiol 280: C1645-C1656, 2001.

4. Conley CA, and Fowler VM. Localization of the human $64 \mathrm{kD}$ autoantigen D1 to myofibrils in a subset of extraocular muscle fibers. Curr Eye Res 19: 313-322, 1999.

5. Conley CA, Fritz-Six KL, Almenar-Queralt A, and Fowler VM. Leiomodins: larger members of the tropomodulin (Tmod) gene family. Genomics 73: 127-139, 2001.

6. Cox PR, and Zoghbi HY. Sequencing, expression analysis, and mapping of three unique human tropomodulin genes and their mouse orthologs. Genomics 63: 97-107, 2000.

7. Doevendans PA, and van Eys G. Smooth muscle cells on the move: the battle for actin. Cardiovasc Res 54: 499- 502, 2002.

8. Dong Q, Ludgate M, and Vassart G. Cloning and sequencing of a novel 64$\mathrm{kDa}$ autoantigen recognized by patients with autoimmune thyroid disease. JClin Endocrin Met 72: 1375-1381, 1991.

9. dos Remedios CG, Chhabra D, Kekic M, Dedova IV, Tsubakihara M, Berry DA, and Nosworthy NJ. Actin binding proteins: regulation of cytoskeletal microfilaments. Physiol Rev 83: 433-473, 2003.

10. El-Mezgueldi M, and Marston SB. The effects of smooth muscle calponin on the strong and weak myosin binding sites of F-actin. J Biol Chem 271:2816128167, 1996.

11. Fischer RS, Fritz-Six KL, and Fowler VM. Pointed-end capping by tropomodulin3 negatively regulates endothelial cell motility. J Cell Biol 161: 371-380, 2003.

12. Fowler VM. Identification and purification of a novel $\mathrm{Mr} 43,000$ tropomyosinbinding protein from human erythrocyte membranes. J Biol Chem 262: 12792$12800,1987$.

13. Fowler VM. Regulation of actin filament length in erythrocytes and striated muscle. Curr Opin Cell Biol 8: 86-96, 1996.

14. Fujisawa T, Kostyukova A, and Maeda $Y$. The shapes and sizes of two domains of tropomodulin, the $\mathrm{P}$-end-capping protein of actin-tropomyosin. FEBS Lett 498: 67-71, 2001. 
15. Gerthoffer WT, and Gunst SJ. Invited review: focal adhesion and small heat shock proteins in the regulation of actin remodeling and contractility in smooth muscle. J Appl Physiol 91: 963-972, 2001.

16. Greenfield NJ, and Fowler VM. Tropomyosin requires an intact N-terminal coiled coil to interact with tropomodulin. Biophys $J$ 82: 2580-2591, 2002.

17. Gusev NB. Some properties of caldesmon and calponin and the participation of these proteins in regulation of smooth muscle contraction and cytoskeleton formation. Biochemistry (Mosc) 66: 1112-1121, 2001.

18. Hodgkinson JL, el-Mezgueldi M, Craig R, Vibert P, Marston SB, and Lehman W. 3-D image reconstruction of reconstituted smooth muscle thin filaments containing calponin: visualization of interactions between $\mathrm{F}$-actin and calponin. J Mol Biol 273: 150-159, 1997.

19. Kostyukova A, Maeda K, Yamauchi E, Krieger I, and Maeda Y. Domain structure of tropomodulin: distinct properties of the $\mathrm{N}$-terminal and C-terminal halves. Eur J Biochem 267: 6470-6475, 2000.

20. Kostyukova AS, and Hitchcock-DeGregori SE. Effect of the structure of the N terminus of tropomyosin on tropomodulin function. $J$ Biol Chem 279: 5066-5071, 2004.

21. Kostyukova AS, Tiktopulo EI, and Maeda Y. Folding properties of functional domains of tropomodulin. Biophys $J$ 81: 345-351, 2001.

22. McElhinny AS, Kolmerer B, Fowler VM, Labeit S, and Gregorio CC. The Nterminal end of nebulin interacts with tropomodulin at the pointed-ends of the thin filaments. J Biol Chem 276: 583-92, 2001.

23. Owens GK. Role of mechanical strain in regulation of differentiation of vascular smooth muscle cells. Circ Res 79: 1054-1055, 1996.

24. Sanders KM. Invited review: mechanisms of calcium handling in smooth muscles. J Appl Physiol 91: 1438-1449, 2001.

25. Smith PG, Roy C, Dreger J, and Brozovich F. Mechanical strain increases velocity and extent of shortening in cultured airway smooth muscle cells. $\mathrm{Am} \mathrm{J}$ Physiol 277: L343-L348, 1999.

26. Sudhir K, Hashimura K, Bobik A, Dilley RJ, Jennings GL, and Little PJ. Mechanical strain stimulates a mitogenic response in coronary vascular smooth muscle cells via release of basic fibroblast growth factor. Am J Hypertens 14: 1128-1134, 2001.

27. Sumpio BE, Banes AJ, Link WG, and Johnson Jr G. Enhanced collagen production by smooth muscle cells during repetitive mechanical stretching. Arch Surg 123: 1233-1236, 1988.

28. Sussman MA, Baque S, Uhm C, Daniels MP, Price RL, Simpson D, Terracio L, and Kedes L. Altered expression of tropomodulin in cardiomyocytes disrupts the sarcomeric structure of myofibrils. Circ Res 82: 94-105, 1998.

29. Watakabe A, Kobayashi R, and Helfman DM. N-tropomodulin: a novel isoform of tropomodulin identified as the major binding protein to brain tropomyosin. J Cell Sci 109: 2299-2310, 1996. 
30. Webb RC. Smooth muscle contraction and relaxation. Adv Physiol Educ 27: 201-206, 2003.

31. Weber A. Actin binding proteins that change extent and rate of actin monomerpolymer distribution by different mechanisms. Mol Cell Biochem 190: 67-74, 1999.

32. Weber A, Pennise CR, and Fowler VM. Tropomodulin increases the critical concentration of barbed end-capped actin filaments by converting ADP.P(i)-actin to ADP-actin at all pointed filament ends. J Biol Chem 274: 34637-34645, 1999.

33. Wilson E, Mai Q, Sudhir K, Weiss RH, and Ives HE. Mechanical strain induces growth of vascular smooth muscle cells via autocrine action of PDGF. $J$ Cell Biol 123: 741-747, 1993.

34. Wong JZ, Woodcock-Mitchell J, Mitchell J, Rippetoe P, White S, Absher M, Baldor L, Evans J, McHugh KM, and Low RB. Smooth muscle actin and myosin expression in cultured airway smooth muscle cells. Am J Physiol 274: L786-L792, 1998. 